\title{
Magnetically Responsive PA6 Microparticles with Immobilized Laccase Show High Catalytic Efficiency in the Enzymatic Treatment of Catechol
}

\author{
Nadya Dencheva ${ }^{1}\left(\mathbb{D}\right.$, Sandra Oliveira ${ }^{1}$, Joana Braz ${ }^{1}$, Dariya Getya ${ }^{2}$, Marc Malfois ${ }^{3}$ (D), Zlatan Denchev ${ }^{1, *(D)}$ \\ and Ivan Gitsov $2,4, *$ (D)
}

check for updates

Citation: Dencheva, N.; Oliveira, S.; Braz, J.; Getya, D.; Malfois, M.; Denchev, Z.; Gitsov, I. Magnetically Responsive PA6 Microparticles with Immobilized Laccase Show High Catalytic Efficiency in the Enzymatic Treatment of Catechol. Catalysts 2021, 11, 239. https://doi.org/10.3390/ catal11020239

Academic Editor: Jose M. Guisan

Received: 26 December 2020

Accepted: 8 February 2021

Published: 11 February 2021

Publisher's Note: MDPI stays neutral with regard to jurisdictional claims in published maps and institutional affiliations.

Copyright: (c) 2021 by the authors. Licensee MDPI, Basel, Switzerland. This article is an open access article distributed under the terms and conditions of the Creative Commons Attribution (CC BY) license (https:/ / creativecommons.org/licenses/by/ $4.0 /)$.
1 IPC-Institute for Polymers and Composites, University of Minho, 4800-056 Guimaraes, Portugal; nadiad@dep.uminho.pt (N.D.); b8223@dep.uminho.pt (S.O.); joanabraz@dep.uminho.pt (J.B.)

2 Department of Chemistry, State University of New York, Syracuse, NY 13210, USA; dgetya@syr.edu

3 ALBA Synchrotron Facility, Cerdanyola del Valés, 0890 Barcelona, Spain; mmalfois@cells.es

4 The Michael M. Szwarc Polymer Research Institute, Syracuse, NY 13210, USA

* Correspondence: denchev@dep.uminho.pt (Z.D.); igivanov@syr.edu (I.G.)

\begin{abstract}
Herewith we report the first attempt towards non-covalent immobilization of Trametes versicolor laccase on neat and magnetically responsive highly porous polyamide 6 (PA6) microparticles and their application for catechol oxidation. Four polyamide supports, namely neat PA6 and such carrying $\mathrm{Fe}$, phosphate-coated $\mathrm{Fe}$ and $\mathrm{Fe}_{3} \mathrm{O}_{4}$ cores were synthesized in suspension by activated anionic ring-opening polymerization (AAROP) of $\varepsilon$-caprolactam (ECL). Enzyme adsorption efficiency up to $92 \%$ was achieved in the immobilization process. All empty supports and PA6 laccase complexes were characterized by spectral and synchrotron WAXS/SAXS analyses. The activity of the immobilized laccase was evaluated using 2,2'-Azino-bis-(3- ethylbenzothiazoline-6-sulfonic acid (ABTS) and compared to the native enzyme. The PA6 laccase conjugates displayed up to $105 \%$ relative activity at room temperature, $\mathrm{pH} 4,40^{\circ} \mathrm{C}$ and $20 \mathrm{mM}$ ionic strength (citrate buffer). The kinetic parameters of the ABTS oxidation were also determined. The reusability of the immobilized laccase-conjugates was proven for five consecutive oxidation cycles of catechol.
\end{abstract}

Keywords: laccase; polyamide 6; enzyme immobilization; magnetic enzyme supports; catechol oxidation

\section{Introduction}

Extracellular enzymes attract nowadays much attention by both industry and academia in the constant search of greener, safer, and more cost-effective alternatives to traditional catalytic systems [1,2]. However, the wide use of industrial-scale processes with enzymatic catalysts is still restricted due to their high sensitivity to $\mathrm{pH}$, temperature, and intolerance to many common organic solvents. Moreover, the complete and fast recovery of enzymes from the reaction medium in order to avoid sensory or toxicological effects, as well as to allow their reuse, is still quite problematic [3]. These limitations can be resolved by immobilization (conjugation) of the enzymes to prefabricated matrices of various nature, geometry, and topography. Immobilized enzymes, apart from their application as reusable heterogeneous biocatalysts, can serve as appropriate platforms for many other advanced applications, e.g., development of biosensors, biofuel cells, design of micro- or nanosized devices for controlled release of protein drugs, among others. [4]

Many immobilization techniques were used for the conjugation of the enzyme to a polymeric support, the most important one being non-covalent adsorption (deposition), entrapment (encapsulation), covalent bonding attachment (tethering), and cross-linking of the enzyme [5]. The immobilization process necessitates a careful control to avoid deactivation of the enzyme. As a rule, the immobilization method is selected on a case-by- 
case basis, although attempts to optimize this process by computer analysis and molecular modelling have also been reported [6,7].

A large variety of supports have been employed for enzyme immobilization in the form of beads, porous particles, membranes and micro- or nanosized fibers. Their composition includes inorganic materials [8] or organic polymers (polyacrylates, cross-linked styrene-based copolymers, smart polymers, or modified polysaccharides [7]). Smart biocatalysts for industrial and biomedical applications produced by conjugation of enzymes to stimuli-responsive polymer supports have attracted a growing interest [9]. The activity of the enzyme can be favorably amplified by complexation with supramolecular lineardendritic block copolymers [10] or amphiphilic block copolymers self-assembling into micelles or physical networks [11].

Among the big variety of industrially relevant enzymes, the group of laccases (EC 1.10.3.2, benzenediol:oxygen oxidoreductases) have generated significant biotechnological interest since they require molecular oxygen as the final electron acceptor and release only water as a by-product [12]. Laccases from different sources can be useful in a large number of applications ranging from food additives and beverage processing to biomedical diagnosis, pulp delignification, wood fiber modification, chemical, or medicinal synthesis, for production of biofuels $[3,13,14]$. Laccases have shown great promise in "green" synthesis and as polymerization mediators [15-18], in industrial effluent treatment including dye decolorization and degradation $[19,20]$, as well as in wastewater and soil remediation [21].

Laccases have been frequently chosen for their ability to chemically modify hazardous phenolic compounds thus limiting the environmental damage. Catechol is one of the most toxic diphenol pollutants of soil and water that is most frequently remediated by laccase [22-24]. Laccase-catalyzed treatment of catechol and other polyphenols toward useful products or processes is well documented, namely polymerization to polycatechols [25-29], oxidation of polyphenols in food industry [30-32] and in-situ dyeing of textile fibers [33-35].

Common synthetic polyamides, such as PA66 and PA6, in the form of films or electrospun nanofibers [36], nanofibrous membranes [37], or woven textiles [38] were shown to be suitable supports for covalently immobilized laccase, the resulting conjugates being useful as biocatalysts, in pollutant detoxification or decolorization of effluents. Very recently, polyamide microparticles (neat, or with various payloads, including magnetic responsive ones) were prepared opening new possibilities for immobilization of biomolecules. For example, Dencheva et al. used activated anionic ring-opening polymerization (AAROP) in suspension of $\varepsilon$-caprolacam (ECL) to produce high yields of neat and magnetically responsive PA6 microparticles (MP) with controlled size, shape, and porosity [39]. Laccaseadsorbed PA6 MP were used for the development of optical biosensor for catechol determination with a detection limit of $11 \mu \mathrm{M}$ and responding linearly to up to $118 \mu \mathrm{M}$ of catechol [40]. With some modification of the published procedure [39], AAROP of $\gamma$-butyrolactam was employed by the same research group to produce neat and magnetic responsive PA4 MP that proved to be effective supports of model proteins [41], in molecular imprinting toward materials for protein recognition [42], or in laccase-containing biocatalysts for dye discoloration [43]. It is worth noting that chemically the polyamide micro particular supports and biomolecules such as proteins, enzymes, RNA oligonucleotides etc. are structural analogues permitting effective hydrogen bond formation in the polyamidebiomolecule conjugate making thereby the effective non-covalent immobilization possible.

This study reports the first attempt towards non-covalent immobilization by adsorption of laccase from Trametes versicolor on neat and magnetically responsive highly porous PA6 particulate supports. These supports include neat PA6 and PA6 carrying Fe microparticles, phosphate-coated Fe microparticles $(\mathrm{FeP})$, or $\mathrm{Fe}_{3} \mathrm{O}_{4}$ nanoparticles synthesized by AAROP of ECL in suspension. The morphology and the crystalline structure of all PA6laccase conjugates were analyzed by microscopy, spectral, and X-ray scattering techniques. The specific and relative enzyme activities as well as the kinetic parameters were assessed using 2,2'-azino-bis (3-ethylbenzothiazoline-6-sulphonic) acid (ABTS) as substrate. All 
PA6-laccase conjugates were tested as biocatalysts for catechol oxidation reusing them in five consecutive cycles.

\section{Results}

Four PA6 supports, without and with magnetic susceptibility, were synthesized by AAROP in suspension as described in Section 3.2. The scheme of the polymerization representing the chemical structure of all substances involved is shown in Figure S1. The microparticulate supports are produced as fine powders with white (PA6), grey (PA6Fe, PA6FeP) or brownish color $\left(\mathrm{PA}_{6} \mathrm{Fe}_{3} \mathrm{O}_{4}\right)$. Laccase from Trametes versicolor was immobilized by physical adsorption on these four supports thereby preparing four conjugates: PA6-L, PA6Fe-L PA6FeP-L, and $\mathrm{PA}_{6} \mathrm{Fe}_{3} \mathrm{O}_{4}-\mathrm{L}$; the generic name for all laccase conjugates being PA6@L.

\subsection{Synthesis and Morphology of the Empty Microparticulate Supports}

Some basic characteristics of the synthesized neat and magnetic PA6 MP are listed in Table 1 . The polymer yields were in the $40-50 \% \mathrm{wt} \%$ range indicating that the presence of iron (0) micro- and iron (II, III) oxide nanosized particles did not affect the activity of $\mathrm{DL} / \mathrm{C} 20$ catalytic system and the kinetics of the AAROP reaction. These yields are determined after the removal of 2.3-3.3 wt\% methanol-soluble oligomers by Soxhlet extraction. Intrinsic viscosity $[\eta]$ (see Supporting Information) of $0.983 \mathrm{dL} / \mathrm{g}$ was found for the neat PA6 MP corresponding to a viscosity- average molecular weight of $27500 \mathrm{~g} / \mathrm{mol}$, which should be the same for all PA6@L conjugates. The magnetic responsive samples were found to include about $6 \mathrm{wt} \%$ of $\mathrm{Fe}$ or $\mathrm{Fe}_{3} \mathrm{O}_{4}$, which is sufficient to impart good magnetic properties to the PA6 MP.

Table 1. Designation and some characteristics of the PA6 microparticles (MP) empty supports.

\begin{tabular}{|c|c|c|c|c|c|c|}
\hline Sample & $\begin{array}{c}\text { PA6 Yield, } \\
\%^{a}\end{array}$ & $\begin{array}{c}\% \text { of } \\
\text { Oligo-mers }\end{array}$ & $\begin{array}{l}\text { Real Fe Content, } \\
R_{L}, \% b\end{array}$ & $\begin{array}{c}{[\eta],} \\
\text { dL.g }\end{array}$ & $\begin{array}{c}\mathrm{d}_{\max }, \\
\mu \mathrm{m}\end{array}$ & $\mathrm{d}_{\max } / \mathrm{d}_{\min }$ \\
\hline PA6 & 47.8 & 2.4 & - & & 30-35 & $1.2-1.4$ \\
\hline PA6Fe & 50.2 & 3.3 & 6.29 & 0.983 & 30-35 & $\begin{array}{l}1.2-1.3 \\
2.1-2.5\end{array}$ \\
\hline PA6FeP & 45.4 & 2.7 & 6.25 & & $\begin{array}{l}30-35 \\
55-60\end{array}$ & $1.1-2.2$ \\
\hline $\mathrm{PA}_{6 \mathrm{Fe}_{3}} \mathrm{O}_{4}$ & 41.5 & 2.3 & 6.05 & & $35-40$ & $1.2-1.3$ \\
\hline
\end{tabular}

${ }^{a}$ In relation to the ECL monomer. ${ }^{b}$ Determined by thermogravimetric analysis (TGA) according to Equation (2) (See Materials and Methods-Section 3.2.

The equivalent circular diameter $d_{\max }$ of the particles in all PA6 empty supports was determined by optical microscopy with image-processing and was found to vary between 15 and $60 \mu \mathrm{m}$ (Table 1, Figure S2 in the Supporting Information). The $d_{\max }$ distributions of PA6, PA6Fe, and PA6FeP are centered in the 30-35 $\mu \mathrm{m}$ interval, while in the latter sample there exist a second group of particles with $d_{\max }$ of 55-60 $\mu \mathrm{m}$. Most of the $\mathrm{PA}_{6 \mathrm{Fe}} \mathrm{O}_{4}$ particles are slightly larger with $d_{\max }$ of $35-40 \mu \mathrm{m}$. The distribution of the roundness parameter $d_{\max } / d_{\min }$ (Table 1, Figure S2) for the Fe- and FeP-containing samples is the broadest ranging from 1.1 to 2.5. Roundness values above 2 can be attributed to selfassembly of magnetized iron fillers to higher aspect ratio aggregates with their subsequent coating with PA6 during the AAROP. Consequently, the iron-loaded MP contain in their cores several iron microparticles, while the $\mathrm{PA}_{6} \mathrm{Fe}_{3} \mathrm{O}_{4} \mathrm{MP}$ would expectedly contain more iron oxide particles in the nanometer length scale.

Details on the morphology of the empty supports' particles can be obtained by SEM (Figure 1). 

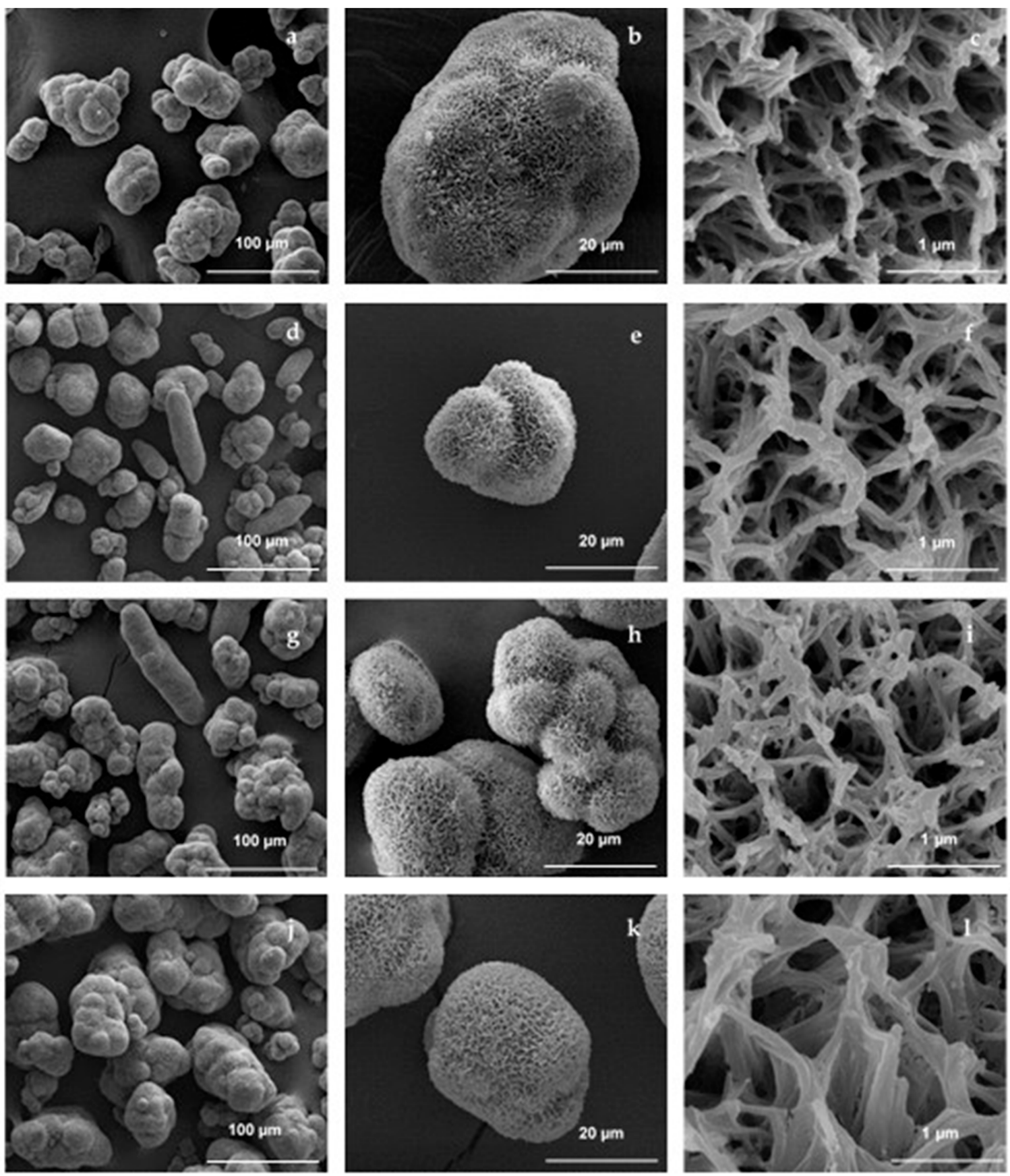

Figure 1. SEM images of empty PA6 particulate supports: (a-c) PA6; (d-f) PA6Fe; (g-i) PA6FeP; (j-l) PA6Fe ${ }_{3} \mathrm{O}_{4}$. The white arrows point to the rod-like morphologies containing Fe or FeP microparticles.

The micrographs of the neat PA6 support (Figure 1a,b) display spheroidal particles with sizes in the 30-35 $\mu \mathrm{m}$ range, i.e., closely correspond to the $d_{\max }$ values in Table 1 . At larger magnifications (Figure 1c), the PA6 particles display porous, scaffold-like topology with visible pore diameters in the range of $350-700 \mathrm{~nm}$. The presence of Fe and FeP particles in PA6 MP (images d-e and g-i, respectively), does not significantly change the surface topology maintaining the same visible pore size. Of particular importance for their use as supports is the interconnected character of the pores potentially enabling efficient multiple site enzyme adsorption and substrate transport. In addition, particles with rodlike morphology appear with average sizes of $30 \times 60-100 \mu \mathrm{m}$ (Figure 1d,g) resulting from coating with PA6 of uniaxially aligned magnetized iron particles which, according to the manufacturer, have diameters of 1.5-3.5 $\mu \mathrm{m}$. Expectedly, no such rods are present 
in the $\mathrm{PA}_{6} \mathrm{Fe}_{3} \mathrm{O}_{4}$ support wherein the iron oxide particles are nanosized $(80-150 \mathrm{~nm})$. As verified in earlier studies on PA6 magnetic responsive microparticles, most of the magnetic particulate fillers (especially the large Fe particles) are embedded in the core of the respective MP [44].

\subsection{Morphology and Laccase Content of the PA6-Laccase Conjugates}

The zeta potential measurements (see the Supporting Information, Table S2) reveal that at $\mathrm{pH} 7$ the microparticles of the four PA6 supports are negatively charged with values between $-28.6 \mathrm{mV}$ (PA6) and $-16.7 \mathrm{mV}$ (PA6FeP). Since the laccase isoelectric point is in the range of $3-4$, at $\mathrm{pH}>4$, the enzyme will be negatively charged as well. Preliminary adsorption tests showed that the largest amounts of laccase are adsorbed at neutral $\mathrm{pH}$, therefore all adsorption experiments were performed at $\mathrm{pH} 7$, in doubly distilled water (DDW). Apparently, the adsorption immobilization of laccase upon PA6 MP is not offset by electrostatic repulsion between the enzyme and the support.

Figure 2 shows the morphology of the PA6@L conjugates as revealed by SEM at various magnifications. The histograms of the conjugate's size- and shape distributions are presented in Figure S3 of the Supporting Information. It seems that the laccase adsorption process that requires shaking for $24 \mathrm{~h}$ and subsequent centrifugation splits the initial MP agglomerates with average diameters of $30-40 \mu \mathrm{m}$ to smaller entities of 3-8 $\mu \mathrm{m}$, whereby the visible surface topology of the conjugates and their roundness remain almost unchanged. Evidently, the adsorbed enzyme is deposited deeply into the pores of the PA6 microparticulate supports and not on their surface.

The next characterization step of the laccase-adsorbed conjugates was to quantify the amount of the adsorbed enzyme. The laccase quantification was based on its UV absorbance in the $280-290 \mathrm{~nm}$ range $[45,46]$ due to the presence of aromatic amino acid residues: tryptophan, tyrosine, or phenylalanine. Thus, all supernatants after adsorption immobilization were studied for residual laccase by UV spectroscopy. As indicated in Table $2,8-23 \%$ of residual laccase was found in the supernatants.

Table 2. Laccase immobilization on PA6 supports—basic data table.

\begin{tabular}{|c|c|c|c|c|c|c|}
\hline Sample & $\begin{array}{l}\text { Residual Laccase } \\
{[\mathrm{mg} / \mathrm{mL}]^{\text {a }}}\end{array}$ & $\begin{array}{l}\text { Laccase on Support, } \\
{[\mathrm{mg}]^{b}}\end{array}$ & $\begin{array}{c}\text { Laccase per g } \\
\text { Support }[\mathrm{mg} / \mathrm{g}]\end{array}$ & $\begin{array}{l}\mathrm{IE}_{r}^{\mathrm{c}} \\
{[\%]}\end{array}$ & $\begin{array}{c}d_{\max } \\
\mu \mathrm{m}\end{array}$ & $\frac{d_{\max }}{d_{\min }}$ \\
\hline PA6-L & 0.17 & 14.6 & 29.3 & 91.5 & $3-6$ & $1.2-1.6$ \\
\hline PA6Fe-L & 0.38 & 12.9 & 25.9 & 80.8 & $4-8$ & $\begin{array}{l}1.2-1.5 \\
2.1-2.5\end{array}$ \\
\hline PA6FeP-L & 0.19 & 14.5 & 29.0 & 90.6 & $4-6$ & $\begin{array}{l}1.2-1.5 \\
2.1-2.5\end{array}$ \\
\hline PA6Fe3O4-L & 0.45 & 12.4 & 24.7 & 77.3 & $4-8$ & $1.2-1.6$ \\
\hline
\end{tabular}

${ }^{a}$ Residual laccase in the supernatant after immobilization determined by standard curve based on the absorbance at $\lambda=286 \mathrm{~nm}$. ${ }^{\mathrm{b}}$ The amounts in this column are arithmetic means of four immobilizations, the standard deviation being in the range of $3-5 \%$. ${ }^{\mathrm{c}}$ Immobilization effectiveness (IE) is the ratio between the amounts of immobilized laccase and starting laccase used in the adsorption process. (see Equation (3), Materials and Methods-Section 3.3.2.).

The maximum amount of laccase $(29.3 \mathrm{mg} / \mathrm{g}$ or $91.5 \%$ from the enzyme amount) was adsorbed by the PA6-L, followed by PA6FeP-L sample with $90.6 \%$ and the PA6Fe-L with $80.8 \%$ immobilization effectiveness (IE). The $\mathrm{PA}_{6 \mathrm{Fe}} \mathrm{O}_{4}-\mathrm{L}$ conjugate displayed the lowest IE of $77.3 \%$. These values are better compared to previous studies on laccase immobilization by covalent bonding on PA6 with IE of 59-71\% [36], or close to that on carbon nanotube supports, i.e., $60-90 \%$ [47]. 

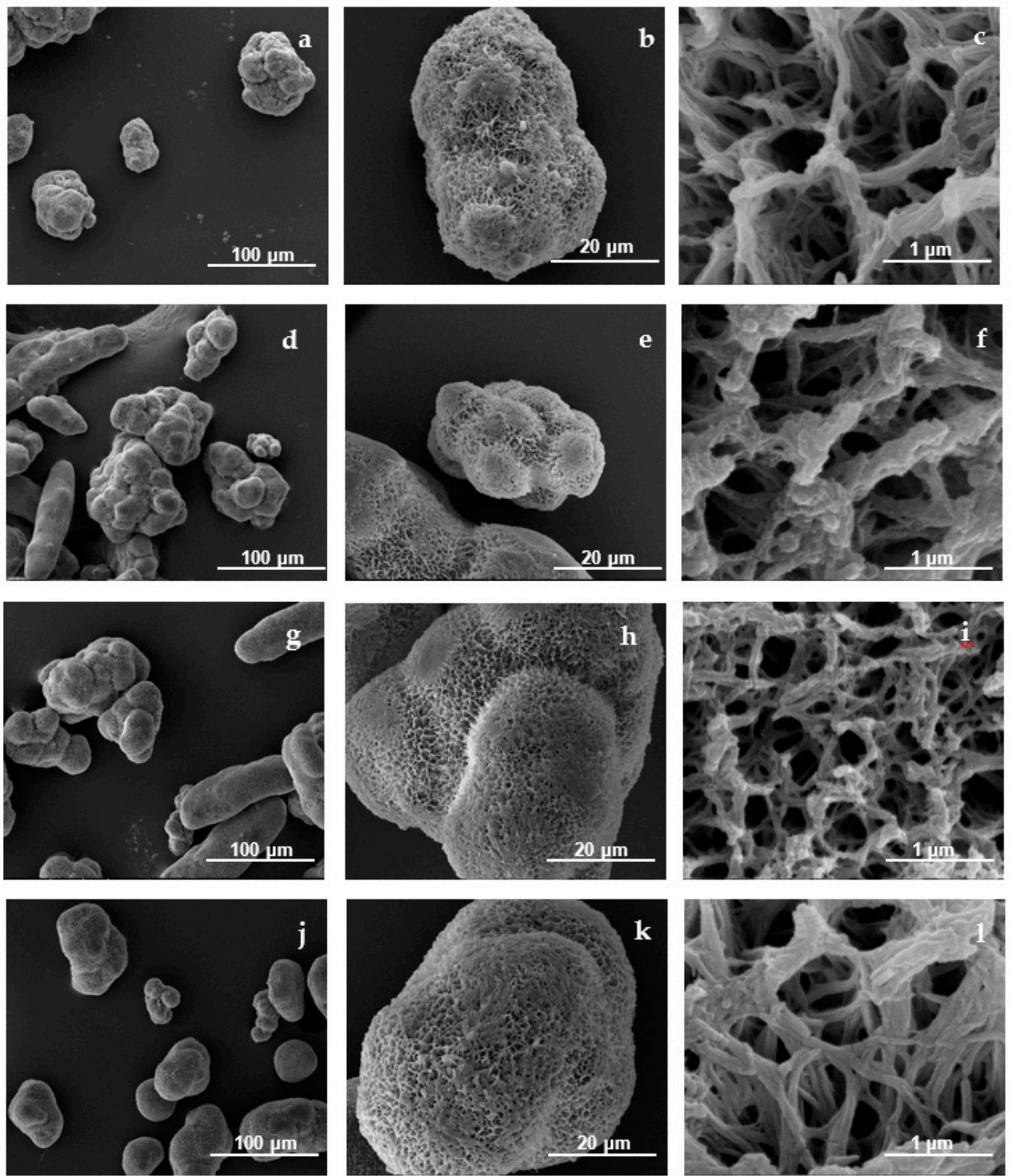

Figure 2. SEM images of laccase-adsorbed PA6 particulate supports: (a-c) PA6-L; (d-f) PA6Fe-L; (g-i) PA6FeP-L; (j-1) $\mathrm{PA}_{6 \mathrm{Fe}} \mathrm{O}_{4}$-L.

Employing the approach of Qui et al. [48], the data in Table 2 can provide information about the mechanism of laccase adsorption on the PA6 supports in this study. Since the size of laccase macromolecule is found to be $6.5 \times 5.5 \times 4.5 \mathrm{~nm}$ [49], its largest footprint on a surface will be $35.8 \mathrm{~nm}^{2}$. The surface areas of the four PA6 supports determined by BET (Table S3 of the Supporting Information) were in the range between $4.56 \mathrm{~m}^{2} / \mathrm{g}$ (PA6 MP) and $7.40 \mathrm{~m}^{2} / \mathrm{g}$ (PA6Fe). Assuming that upon adsorption laccase molecules arrange in ideal monolayers and that the laccase molecular weight is approximately $68 \mathrm{kDa}$, then $1.0 \mathrm{~g}$ of PA6 support should theoretically adsorb between $14.3 \mathrm{mg}$ (PA6 MP) and $23.4 \mathrm{mg}$ (PA6Fe) of enzyme. According to Table 2, the experimental values vary in the $24.7-29.3 \mathrm{mg}$ range. Consequently, the laccase adsorption on PA6Fe support should occur almost in monolayers; on $\mathrm{PA} 6$ - in bilayers, while on $\mathrm{PA}_{6} \mathrm{Fe}_{3} \mathrm{O}_{4}$ and $\mathrm{PA} 6 \mathrm{FeP}$ the number of layers would vary between 1.3 and 1.7, respectively. A comparison can be made with laccase immobilized PA4 MP in our previous study [43] where deposition of laccase was found to occur in 4-5 layers. It should be noted that the deposition of the enzyme in ideal monolayers should 
be considered optimal, since no screening of the active centers or blockage of sites by upper layers will occur.

\subsection{Structure Characterization of PA6 Empty Supports and Laccase Conjugates}

The PA6 porous microparticles obtained by AAROP have been extensively studied in previous publications $[39,44]$. In this work, we will focus only on those characteristics of the laccase-PA6 conjugates that could be related to their catalytic activity.

\subsubsection{FTIR Spectroscopy}

A FT-IR spectra comparison between the empty PA6 support, PA6-L, and the neat, lyophilized laccase is presented in Figure 3. The narrow peaks at $3294 \mathrm{~cm}^{-1}$ in the neat PA6 support (trace 1) and in PA6-L (trace 2) were assigned to the valence stretching vibrations in secondary $\mathrm{NH}$ groups belonging to PA6. Both spectra also show well-defined peaks for Amide I at 1633-1635 $\mathrm{cm}^{-1}$ and Amide II at $1535 \mathrm{~cm}^{-1}$. This is a clear indication for fixation of the trans-conformation of the -NH-CO- group, being typical for high molecular weight polyamides. The laccase spectrum (trace 3 ) displays a strong broad band centered at $3315 \mathrm{~cm}^{-1}$ (characteristic of associated N-H bonds different than those in PA6), a weak peak at $1643 \mathrm{~cm}^{-1}$ attributable to amide groups in the laccase peptide chains, and a complex band centered at $1014 \mathrm{~cm}^{1}$. The spectrum of PA6-L sample in the $4000-1500 \mathrm{~cm}^{-1}$ zone is a superposition of curves 1 and 3, the slight shift of its Amid I band being a result of a combination of the latter with the weak laccase peak band. Notably, the strong complex peak at $1014 \mathrm{~cm}^{-1}$ of the lyophilized laccase is not present in the adsorption-immobilized laccase conjugate. A similar effect was observed in laccase-immobilized PA4 MP [43].

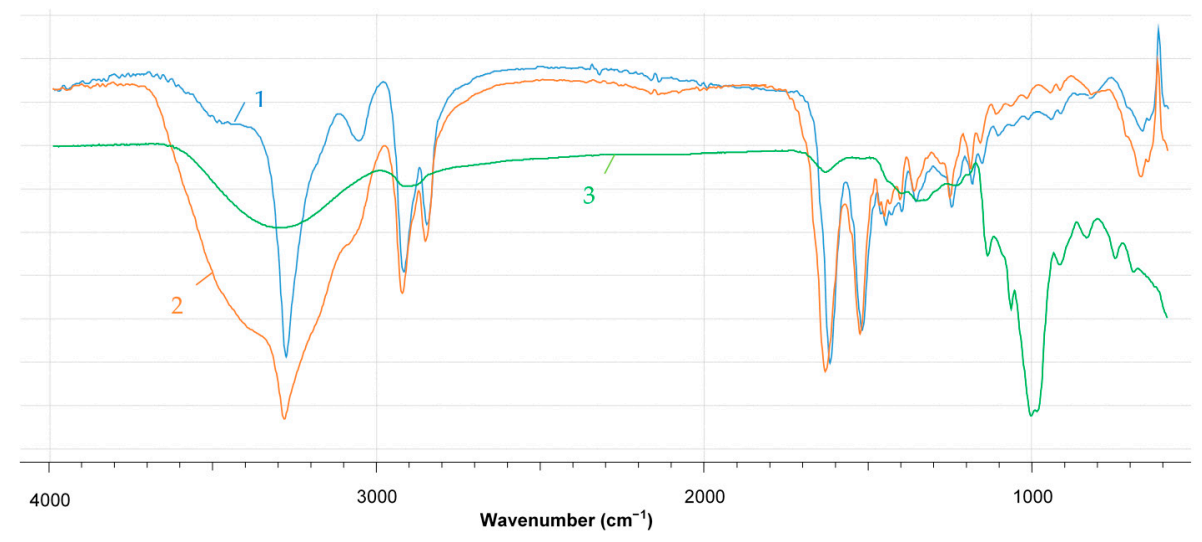

Figure 3. FTIR spectra with ATR of representative samples: 1-empty PA6 support; 2-PA6-L; 3-native laccase.

\subsubsection{Synchrotron WAXS}

The activity of laccase physically adsorbed onto PA6 MP and the efficiency of the immobilization process in each case will directly depend on the nature and strength of the interactions at the enzyme/PA6 support interface. The postulated intense H-bond formation between laccase and the polyamide support, which is its structural analogue, should have some influence on the enzyme configuration, or the crystalline structure of the polymeric support that can be probed by X-ray scattering techniques. It is also important to know whether or not the interior pores and channels of the PA6 MP that are impossible for direct SEM observation are filled with enzyme. Synchrotron WAXS and SAXS were employed in an attempt to evaluate these factors in the empty PA6 supports and in the respective PA6@L conjugates.

Figure 4 shows the comparison between the linear WAXS patterns of samples representing the four empty supports, as well as the four immobilized laccase samples. All WAXS patterns display two strong reflections at $q \approx 14.2 \mathrm{~nm}^{-1}$ and $16.9 \mathrm{~nm}^{-1}$ that should be ascribed to the monoclinic unit cell of the $\alpha$-PA6 with $\mathrm{d}_{\alpha[200]}=4,43 \AA$ and $\mathrm{d}_{\alpha[002 / 202]}=3.73 \AA$. 
The visual inspection of the WAXS patterns of the PA6 supports in Figure 4a suggest that the presence of $\mathrm{Fe}, \mathrm{FeP}$, or $\mathrm{Fe}_{3} \mathrm{O}_{4}$ fillers does not seem to change the crystalline structure maintaining unaffected the angular position and the relative intensities of the two $\alpha-\mathrm{PA} 6$ reflections.
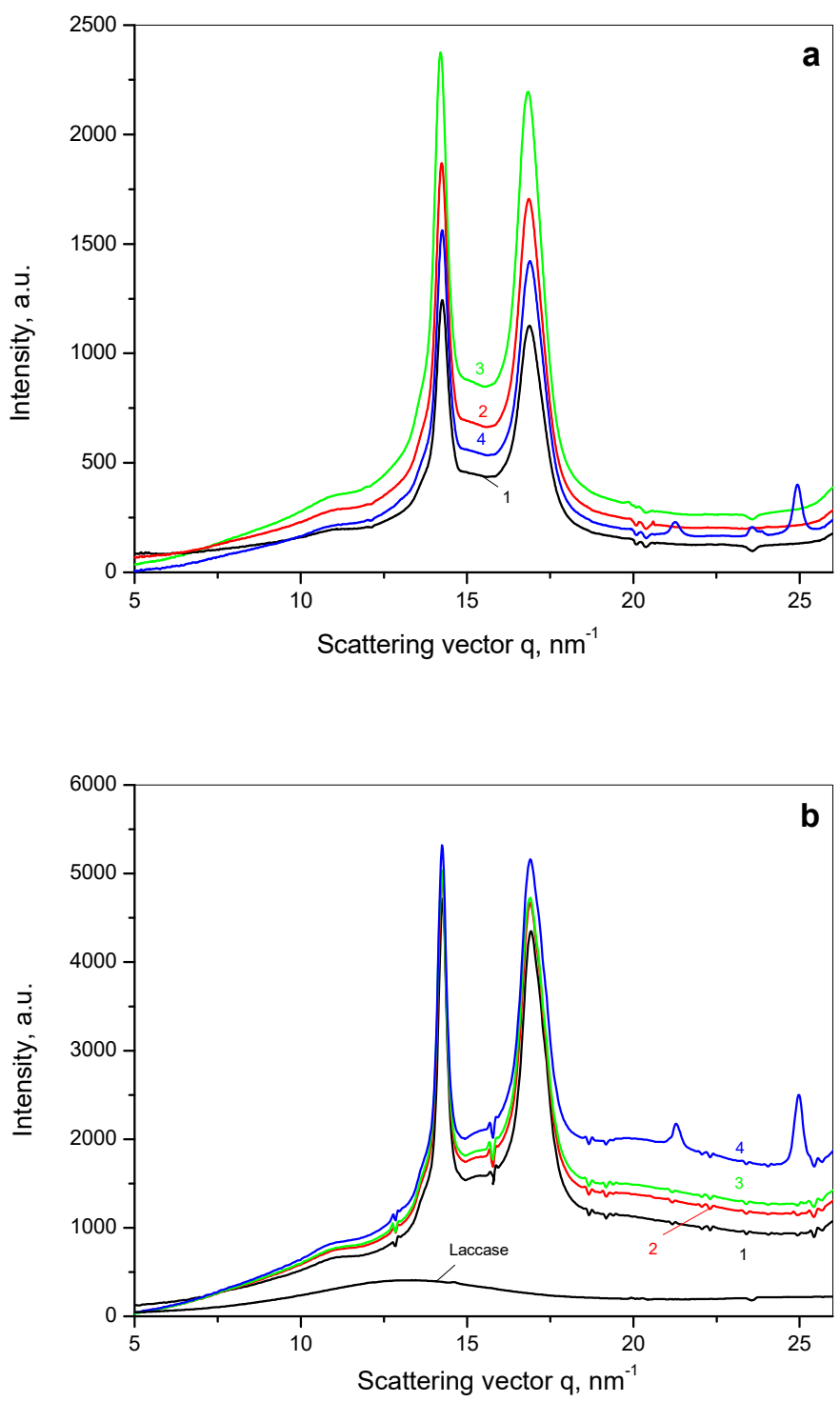

Figure 4. Background-corrected linear WAXS patterns of: (a) Neat PA6 supports; (b) PA6@L samples; 1-PA6; 2-PA6Fe; 3-PA6FeP; 4- $\mathrm{PA}_{6} \mathrm{Fe}_{3} \mathrm{O}_{4}$. The laccase WAXS pattern is also shown in subfigure $\mathrm{b}$ his is a figure. Schemes follow the same formatting.

The patterns of the PA6@L samples presented in Figure $4 \mathrm{~b}$ display no significant change of the form or position of two reflections assigned the monoclinic $\alpha$-PA6. However, after laccase adsorption, a hump in the baseline appears at higher $q$-values due to an additional diffuse scattering (halo) related to the adsorbed laccase. Figure $4 \mathrm{~b}$ also displays the pattern of the free laccase producing a wide scattering peak typical of disordered materials centered at $q_{a}^{\text {free }}=12.9 \mathrm{~nm}^{-1}$. This means that the free lyophilized laccase is amorphous at the length scale of various angstroms that is probed by WAXS.

Further information about the crystalline structure of the samples can be extracted after deconvolution of the WAXS patterns in Figure 5 by peak fitting. This procedure and the subsequent quantification of the PA6 polymorphs is made as indicated earlier [50]. All structural information from the fitted WAXS patterns of the laccase conjugates is presented in Table 3. 

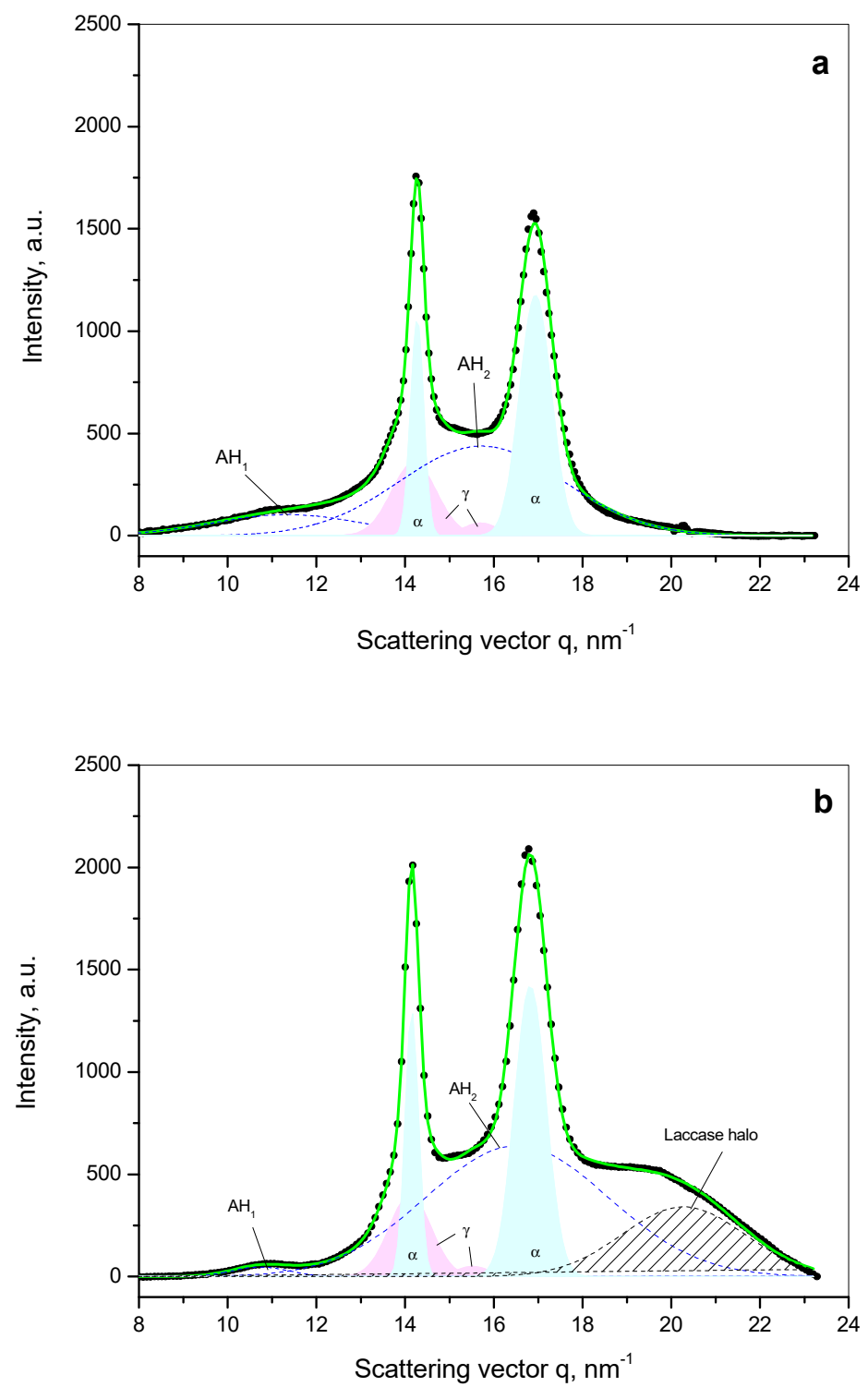

Figure 5. Selected wide-angle X-ray scattering (WAXS) patterns with background correction exemplifying deconvolution by peak-fitting: (a) Neat PA6 support; (b) PA6-L conjugate. $\mathrm{AH}_{1}$ and $\mathrm{AH}_{2}$ - diffuse peaks of the PA6 amorphous fraction $\mathrm{s}$ is a figure.

Table 3. WAXS analysis of empty PA6 supports and PA6-laccase conjugates.

\begin{tabular}{|c|c|c|c|c|c|c|}
\hline Sample & $\underset{\%}{\alpha-P A 6}$ & $\underset{\%}{\gamma \text {-PA6 }}$ & $X_{c}^{W A X S} \%$ & $\alpha / \gamma$ & $q_{a}^{i m m} \mathbf{n m}^{-1}$ & $\Delta q_{a} \mathbf{n m}^{-1}$ \\
\hline Laccase & - & - & - & - & 12.9 & 0.0 \\
\hline PA6 & 32.7 & 11.6 & 44.3 & 2.82 & - & - \\
\hline PA6-L & 20.7 & 17.6 & 44.1 & 1.18 & 19.5 & 6.7 \\
\hline PA6Fe-L & 20.8 & 13.8 & 40.0 & 1.51 & 19.7 & 6.8 \\
\hline PA6FeP-L & 19.9 & 14.3 & 40.0 & 1.39 & 20.0 & 7.1 \\
\hline $\begin{array}{c}\mathrm{PA}_{6 \mathrm{Fe}_{3} \mathrm{O}_{4}-} \\
\mathrm{L}\end{array}$ & 20.1 & 18.1 & 43.2 & 1.11 & 19.5 & 6.6 \\
\hline
\end{tabular}

Notes: The bolded values for $X_{c}^{W A X S}$ are determined excluding the adsorbed laccase amorphous reflection; $\Delta q_{a}=q_{a}^{i m m}-q_{a}^{f r e e} ; X_{c}^{\text {WAXS }}=$ WAXS crystallinity index. For more information, see the text.

All deconvolutions of the samples in this study show that excellent fits with regression coefficients $R^{2} \geq 0.99$ were only possible if along with the two peaks of $\alpha-\mathrm{PA} 6$ and the two amorphous halos $\mathrm{AH}_{1}$ and $\mathrm{AH}_{2}$, two more crystalline peaks were considered that should 
be assigned to an additional crystalline phase designated as $\gamma$-PA6 with pseudo-hexagonal unit cell. The two PA6 polymorphs coexist and their relative content varies as a function of the thermal prehistory and sample composition [50,51]. Table 3 displays structural data extracted by deconvolution of the WAXS profiles of the PA6@L samples. In all of them, the amorphous halo of the immobilized enzyme appears at $q_{a}^{i m m} \approx 20 \mathrm{~nm}^{-1}$. This shift $\Delta q_{a} \approx 7 \mathrm{~nm}^{-1}$ is significant and can be explained as follows. The laccase amorphous halo is attributable to the adsorbed bulk laccase deposited on the surface and/or within the pores of the PA6 particulate support. Since the amorphous halo in WAXS is related to intermolecular interactions [52], its position must be dependent on the degree of packing of the molecules (i.e., the density) of the respective amorphous phase. As pointed out by Alexander [53], the dependence of the amorphous halo angular position $q_{a}$ on the intermolecular distance $r_{a}$ is given as:

$$
r_{a} \sim \frac{\lambda}{2 q_{a}}, \mathrm{~nm}
$$

which is the reciprocal dependence typical of all diffraction phenomena. Thus, the larger the scattering vector $q_{a}$, value is, the smaller the intermolecular distance and consequently the higher the density of this amorphous phase will be. Therefore, the higher the $\Delta q_{a}$ values in Table 3, the denser the packing of the immobilized laccase upon the PA6 support as compared to the free enzyme. This densification can only be explained with more intensive interaction between the laccase and the support via multiple $\mathrm{H}$-bonds. In this context, in all PA6@Lsamples $\Delta q_{a}$ is the largest in the PA6FeP-L, followed by the PA6Fe-L, the PA6-L, and the $\mathrm{PA}_{6} \mathrm{Fe}_{3} \mathrm{O}_{4}$-L samples. In accordance with Equation (1), in this sequence, the density of the adsorbed bulk laccase decreases. Notably, with the PA6FeP-L sample the zeta potential is the least in absolute value, meaning that here the repulsion between the MP and laccase will be the weakest.

The $\alpha / \gamma$ ratio in the empty PA6 support is 2.82 and decreases to values in the 1.51-1.11 range after laccase adsorption in the PA6@L samples. This means that the PA6-laccase interaction via hydrogen bonds may cause some slight rearrangement of the crystalline phase leading to $\alpha-\gamma$ transition.

\subsubsection{Synchrotron SAXS}

The use of synchrotron SAXS allows further clarification of the structure of the PA6 MP before and after laccase immobilization. This method probes density periodicities with dimensions in the 20-250 angstroms range, which includes the sizes of the crystalline lamellae typically found in semi-crystalline polymers. Figure 6 displays the SAXS linear profiles of the three empty and the respective PA6@L samples. To enable comparison, the SAXS curve of the free laccase is also presented in Figure 6d.

All four empty PA6 supports in Figure 6a do not display resolved Bragg peaks. This finding is in conflict with the $X_{c}^{\text {WAXS }}$ values of close to $44 \%$ found in the neat PA6 support, which means presence of predominantly crystalline lamellar stacks. Thus, the 1D-correlation functions $\gamma_{1, \mathrm{r}} / Q$ were computed from the SAXS profiles (for details see [50] and the references therein) of the free supports (Figure $6 \mathrm{c}$ ). The latter undoubtedly demonstrated the presence of lamellar periodicity with Bragg long spacings $L_{B}$ of $80 \AA$ (for

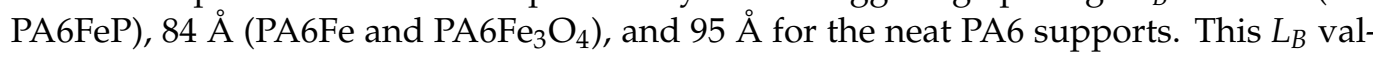
ues range is typical of annealed isotropic PA6 [50]. As seen from Figure 6c, curve 3 , this two-phase lamellar system is the most perfect in the PA6FeP support, whose correlation function displays the best-expressed first maximum, i.e., the density distribution is the narrowest with more homogeneous and perfect lamellar structure. 

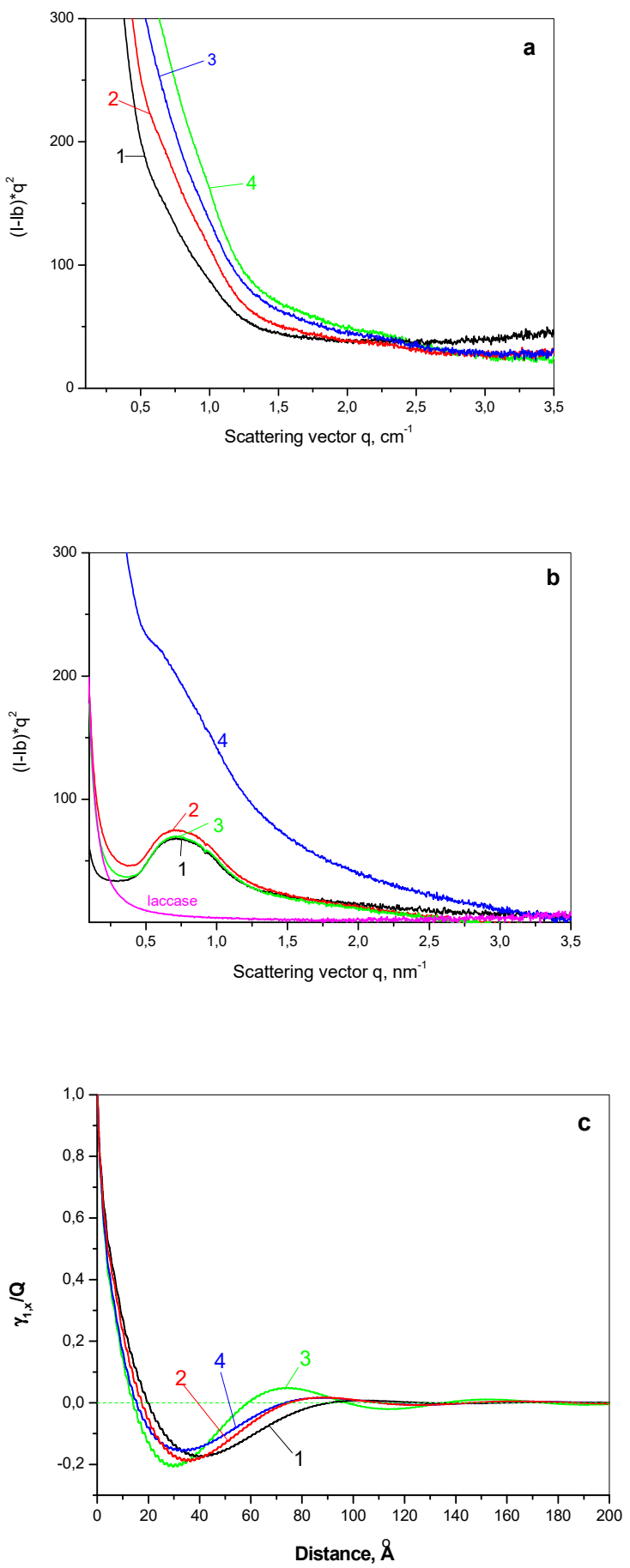

Figure 6. Linear SAXS patterns after background subtraction and Lorentz correction of: (a) Empty PA6 supports; (b) PA6@L and (c) linear correlation function of the empty supports. 1-PA6; 2-PA6Fe; 3-PA6FeP; $4-\mathrm{PA}_{6} \mathrm{Fe}_{3} \mathrm{O}_{4}$. The laccase pattern is presented in Figure $6 \mathrm{~b}$ for comparison. For more detail see Materials and Methods-Section 3.2 and Ref. [50].

As seen from the SAXS patterns in Figure $6 \mathrm{~b}$, the amorphous free laccase does not show any periodicity in the SAXS $q$-range. Nevertheless, the laccase-adsorbed supports, with the exception of the $\mathrm{PA}_{6} \mathrm{Fe}_{3} \mathrm{O}_{4}$-L sample, display very well-resolved SAXS peaks with $L_{B}=86 \AA$. This evidences a much better phase contrast between the densities of the amorphous and crystalline regions, as compared to the respective neat PA6 supports (Figure 6a). Therefore, the SAXS curves in Figure $6 \mathrm{~b}$ allow the conclusion that after laccase immobilization most of the pores and channels of the empty supports get filled with 
enzyme whose density should be comparable to that of the amorphous PA6. This creates a clearer density gradient between the amorphous and crystalline fractions of the lamellar periodicity resulting in a better resolved SAXS peaks in the PA6@L samples. This effect does not occur in the $\mathrm{PA}_{6} \mathrm{Fe}_{3} \mathrm{O}_{4}$-L sample, most probably because in that conjugate the amount of the adsorbed laccase is the smallest (see Table 2, column 5).

\subsubsection{Magnetization Studies}

The two Fe-containing PA6FeP and PA6Fe supports were studied in a vibrating sample magnetometer (VSM) at $23{ }^{\circ} \mathrm{C}$. Notably, their magnetization curves were similar to that of the pure Fe (Figure S4 in the Supplementary Materials). The saturation values of the two PA6 supports were $13.44 \mathrm{emu} / \mathrm{g}$ and $12.70 \mathrm{emu} / \mathrm{g}$, respectively. With a saturation value of the neat Fe powder of $196 \mathrm{emu} / \mathrm{g}$, the content of the ferromagnetic material in the two supports was found to be in the $6.5-6.8 \%$, almost coinciding with that found by TGA (Table 1). Evidently, the VSM data of the PA6-based supports are strictly proportional to their Fe content without other changes in the hysteresis loop.

\subsection{Enzymatic Activity of PA6@L Conjugates}

The catalytic activity of all PA6@L conjugates was studied using ABTS substrate in $20 \mathrm{mM}$ citrate buffer (CB), pH 4, at room temperature (Table 4). Data on the total, specific, and relative activities of each PA6@L sample are presented considering the free laccase activity as $100 \%$. The PA6@L samples contain in average $0.025-0.030 \mathrm{mg}$ enzyme per $\mathrm{mg}$ of support. Generally, the specific activity of the immobilized laccase (Table 4, column 3) in all conjugates is very close to that of the free laccase, and in the case of PA6FeP-L the relative activity (column 5 ) is with about $6 \%$ higher. This result can be considered quite good keeping in mind that the immobilized laccases display typically lower activities than the free ones due to limited mass transfer and obstruction of the $\mathrm{Cu}$ active centers [54]. The activities of the PA6@L samples compare favorably to the results obtained with similar systems based on PA4 [43], in which the immobilized laccase was 1.7-2.6 times less active than the free enzyme. This effect can be attributed to the much larger pores on the surface of the PA6 MP (350-700 nm versus 100-150 nm in the PA4 MP supports), causing less mass-transfer limitations.

Table 4. Specific activity and kinetics parameters of free and immobilized laccase.

\begin{tabular}{|c|c|c|c|c|c|c|}
\hline Sample & $\begin{array}{c}\text { Laccase Activity } \\
{\left[\mu \mathrm{kat} \mathrm{L}^{-1}\right]}\end{array}$ & $\begin{array}{c}\text { Specific } \\
\text { Activity per } \\
\text { mg Laccase }\end{array}$ & $\begin{array}{c}\text { Specific } \\
\text { Activity per } \\
\text { mg lacc. and } \\
\text { mg MP }\end{array}$ & $\begin{array}{c}\text { Relative } \\
\text { Laccase } \\
\text { Activity, [\%] }\end{array}$ & $\begin{array}{l}K_{m} \\
\mathbf{m M}\end{array}$ & $\begin{array}{c}V_{\max } \\
{\left[\mu \mathrm{mol} \mathrm{L}^{-1} \mathrm{~s}^{-1}\right.} \\
\left.\operatorname{mg~lacc}^{-1}\right]\end{array}$ \\
\hline Free laccase & 2.67 & 22.23 & - & 100.0 & 0.27 & 5.48 \\
\hline PA6-L & 2.37 & 18.13 & 3.63 & 81.5 & 0.70 & 5.99 \\
\hline PA6Fe-L & 2.67 & 20.82 & 4.16 & 93.6 & 1.46 & 8.71 \\
\hline PA6FeP-L & 3.39 & 23.49 & 4.70 & 105.7 & 4.31 & 9.74 \\
\hline $\mathrm{PA}_{6} \mathrm{Fe}_{3} \mathrm{O}_{4}-\mathrm{L}$ & 2.60 & 21.25 & 4.25 & 95.6 & 2.42 & 6.03 \\
\hline
\end{tabular}

Note: Laccase activity toward $0.1 \mathrm{~mL}$ ABTS $\left(5 \mathrm{mM}\right.$ in DDW), CB $\left.20 \mathrm{mM}, \mathrm{pH} 4,25^{\circ} \mathrm{C}\right) . K_{m}$ and $V_{\max }$ are kinetic parameters determined in accordance with the Lineweaver-Burk double reciprocal model (Equation (4) in Section 3.3.4. of the Materials and Methods). Each value in column 1 is the mean of 4 independent measurements with a maximal standard deviation of $5 \%$.

Table 4 also shows that, in general, the conjugates carrying ferromagnetic fillers display higher relative enzyme activity, most probably due to some synergism between the $\mathrm{Cu}$-containing laccase active centers and the iron $\mathrm{Fe}^{0,+2,+3}$ from the carrier observed by Arantes et al. [55]. The PA6FeP-L sample that displays the highest relative activity of $>105 \%$ has shown the largest enzyme densification on the MP support measured by WAXS (Table 3, $\Delta q=7.1 \mathrm{~nm}^{-1}$ ). Apparently, the denser packing of the laccase due to more intense H-bond formation with the PA6 support is more important for the relative activity than its internal area, which is the largest in the PA6Fe MP (Table S3) 
The kinetic parameters $K_{m}$ and $V_{\max }$ of the enzymatic oxidation of ABTS substrate by free and immobilized laccase are also presented in Table 4 . Theoretically, $K_{m}$ is inversely related to ABTS binding to the enzyme, whereas $V_{\max }$ is directly related to the catalytic power of the enzyme in transforming ABTS to oxidation products. As seen from Table 4, the $K_{m}$ values for all PA6@L samples are significantly higher than that of the free laccase-from 2.6 times for the PA6-L to more than 16 times for the PA6FeP-L support. These results are in agreement with earlier studies on immobilized laccase [56] explained with decreased flexibility of the enzyme after immobilization. Such an explanation correlates perfectly with our WAXS data suggesting the highest laccase densification in the PA6FeP-L and the lowest in the PA6-L sample. Considering the $V_{\max }$ parameter, however, all immobilized PA6@L samples in Table 4 showed higher values than the free enzyme decreasing in the order: PA6FeP-L $>$ PA6Fe-L $>\mathrm{PA}_{6} \mathrm{Fe}_{3} \mathrm{O}_{4}-\mathrm{L}>\mathrm{PA} 6-\mathrm{L} \geq$ free laccase. Apparently, the immobilization of laccase on PA6 MP decreases its affinity to ABTS, depending on the type of the magnetic filler used. At the same time and exactly in the same order, laccase immobilization enhances the catalytic power for the same substrate. This can be explained by the fact that binding and catalysis are two distinct steps in enzyme action that are related to different sites. Thus, it can be hypothesized that in all PA6@L there is some distortion of the enzyme's binding site leading to lower substrate affinity. This same distortion leads to an optimization of the catalytic site resulting in more effective substrate oxidation. Ones again, the PA6FeP-L conjugate proved to be the best catalytic system.

Furthermore, we studied the influence of the $\mathrm{pH}$, the ionic strength of the citrate buffer, and the temperature on the activity of the free and immobilized laccase using ABTS. The objective was to optimize the conditions of use of the PA6@L conjugates and to compare their action to the free laccase in all of the cases studied. Thus, Figure 7 displays the dependence of the laccase activity as a function of $\mathrm{pH}$ in the range of $\mathrm{pH}$ values between 3-7. The specific activity normalized per $1 \mathrm{mg}$ laccase for all conjugates and the free laccase are compared in Figure 7a. The relative activity represented as percentage of that of the free laccase (taken as $100 \%$ ) is compared in Figure $7 \mathrm{~b}$.
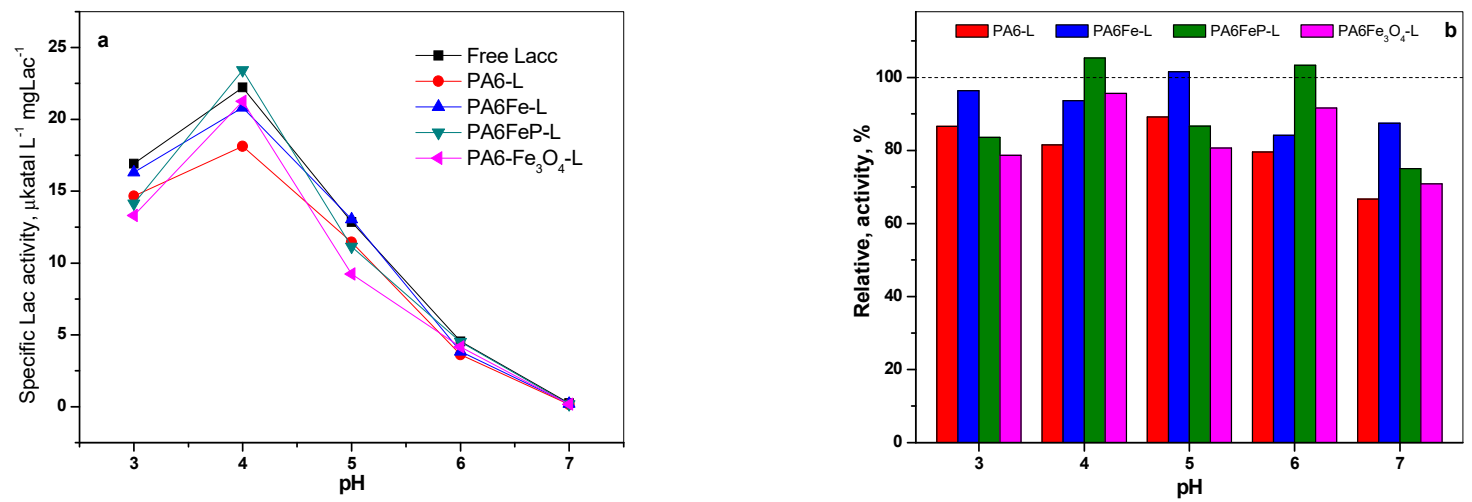

Figure 7. Influence of $\mathrm{pH}$ on the activity of free laccase and PA6@L conjugates: (a) Specific laccase activity and (b) relative laccase activity as a function of $\mathrm{pH}=3-7$. Conditions: $\mathrm{CB} 20 \mathrm{mM}, 37^{\circ} \mathrm{C}$. The black dash line in Figure $7 \mathrm{~b}$ shows the $100 \%$ level of the free laccase.

As seen from Figure 7, laccase activity is strongly dependent on the $\mathrm{pH}$ value and exhibits the highest activity at $\mathrm{pH} 4-5$, i.e., around its isoelectric point. The PA6Fe-L and PA6FeP-L samples even showed slightly increased activity as compared to free laccase. This can be due to some synergism between $\mathrm{Fe}^{0}$ and $\mathrm{Cu}$ active sites of the laccase already noted in the comments to Table 4 . This effect was less pronounced with the $\mathrm{PA}_{6} \mathrm{Fe}_{3} \mathrm{O}_{4}-\mathrm{L}$ sample, that contains $\mathrm{Fe}^{2+} / \mathrm{Fe}^{3+}$ ions. It is noteworthy that in the wider $\mathrm{pH}$ range of 3-6, the PA6@laccase conjugates retain more than $80 \%$ of their activity.

In a similar way, the influence of the ionic strength of the CB varied in the $10-100 \mathrm{mM}$ range and that of the temperature $\left(25-60^{\circ} \mathrm{C}\right)$ upon the specific and relative activity was 
followed for all conjugates and the free laccase. The optimum value of the ionic strength was $20 \mathrm{mM}$ (Figure 8). As seen from Figure 9, the relative activity of immobilized laccase at elevated temperatures $\left(50\right.$ and $60^{\circ} \mathrm{C}$ ) is $2-15$ times higher compared to that of the free enzyme, which justifies its immobilization, the optimum value being at $40^{\circ} \mathrm{C}$.
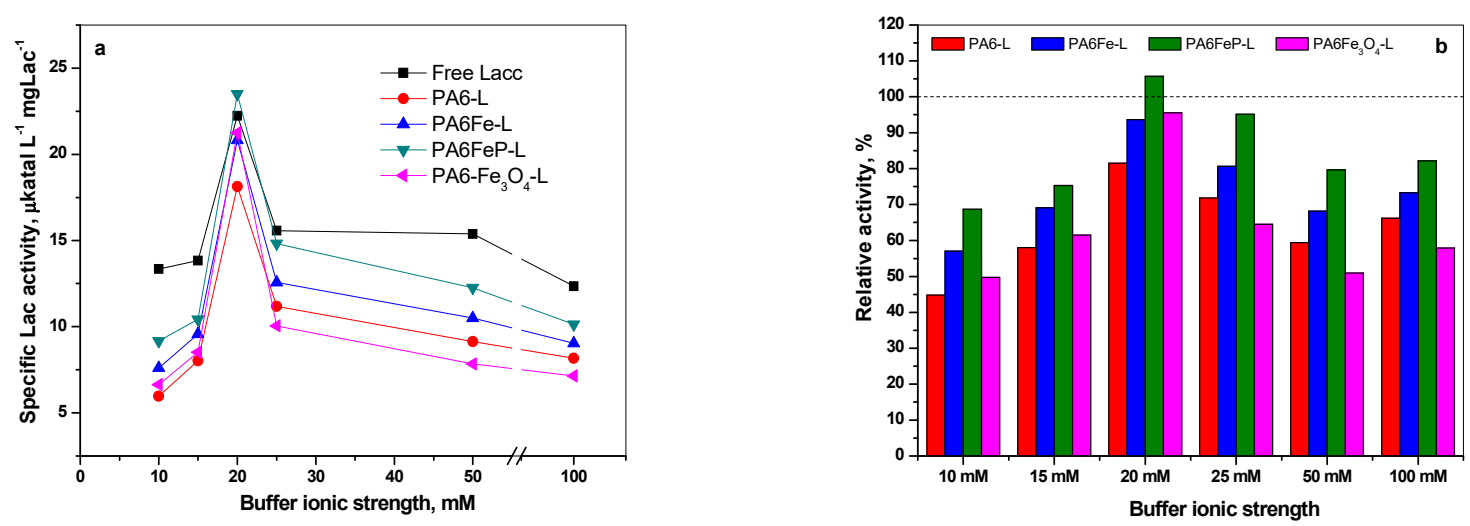

Figure 8. Influence of ionic strength of the buffer on the activity of free laccase and PA6@L conjugates: (a) Specific laccase activity and (b) relative laccase activity. Conditions: $\mathrm{CB} 10-100 \mathrm{mM}, 37^{\circ} \mathrm{C}$.
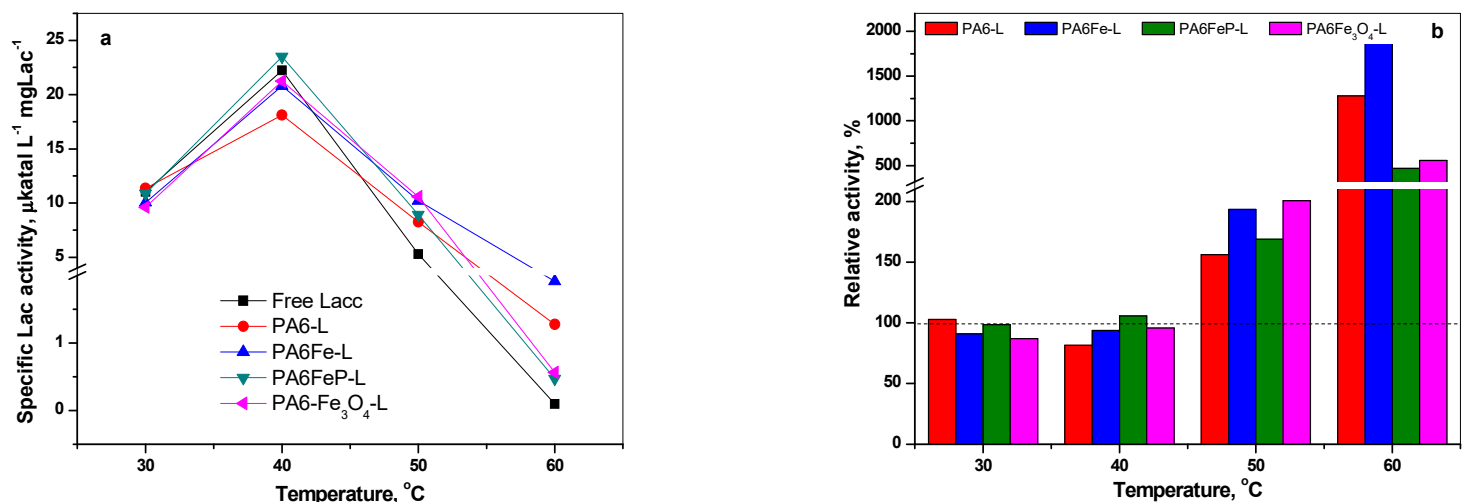

Figure 9. Influence of temperature of incubation on the activity of free laccase and PA6@L conjugates: (a) Specific laccase activity and (b) relative laccase activity.

\subsection{Oxidation of Catechol by PA6@L Conjugates}

As mentioned in the Introduction, laccases have been used extensively for transformation of the toxic catechol to polymeric products [25-29]. Some studies related to the mechanism of this synthesis showed that this is a two-step process including (i) enzymatic oxidation of catechol to $o$-benzoquinone, and (ii) non-enzymatic reactions of polymerization of the latter to higher molecular weight products [34,57]. As shown by Sun et al. [58], the amounts of the forming benzoquinone can be quantified by UV-VIS based on the absorption peak at $\lambda=410 \mathrm{~nm}$ typical of the conjugated quinonic system that is absent in the starting catechol. This makes it possible to follow the kinetics of the enzymatic reaction directly.

Figure 10 displays the combined results of these kinetic studies. The evolution of the quinone absorption peak with time in the presence of native laccase is shown in Figure 10a, and in the process catalyzed by the PA6FeP-L conjugate-in Figure 10b, as a representative example for all PA6@L samples. Figure 10c presents the respective time dependence curves $A_{\max }^{410}=f(t)$ for all PA6@L conjugates and for the native laccase, wherein $A_{\max }^{410}$ is the UV-VIS absorption at $\lambda=410 \mathrm{~nm}$. Figure 10d visualizes the deepening of color in the cuvette with the catechol solution due to the action of the magnetic sensitive PA6@L laccase conjugate, as well as the separation of the latter from the reaction medium by a constant 
magnet. The rate constants of the enzymatic oxidation caused by all samples studied are also represented in Figure 10d. They were calculated as the slope of the linear segments of the time dependencies in Figure 10c (0-45 min interval). The spectral study on the laccase-catalyzed catechol oxidation reveals high rate constants for the PA6-L, PA6Fe-L and PA6FeP-L conjugates, most of them being very close to or even slightly higher than that of the free laccase. Only the rate constant of the $\mathrm{PA}_{6 \mathrm{Fe}} \mathrm{O}_{4}-\mathrm{L}$ sample is statistically lower. All these results are in good agreement with the previous data of this study on the laccase content, activity, and densification on the respective PA6 supports.
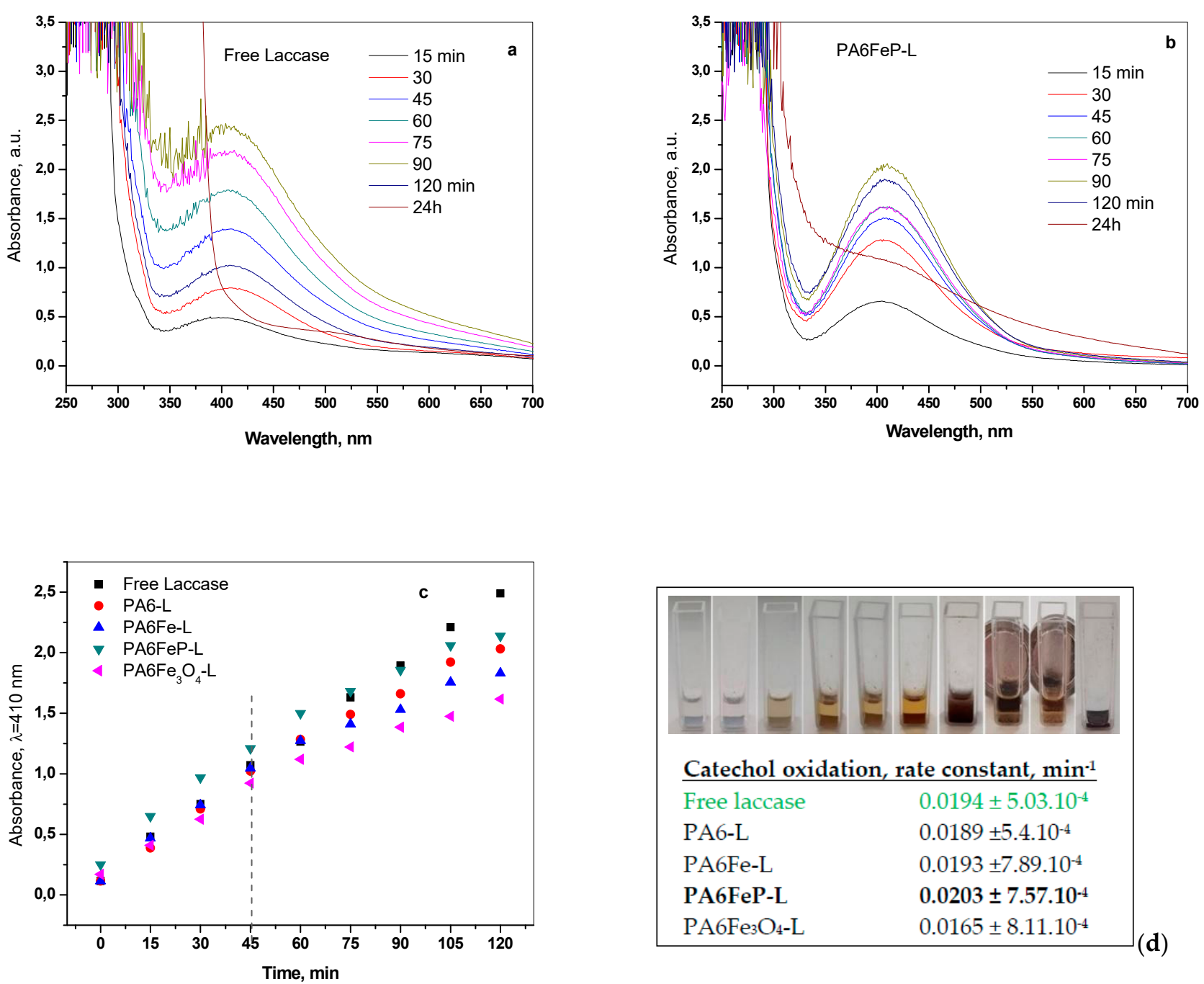

Catechol oxidation, rate constant, $\mathrm{min}^{-1}$

\begin{tabular}{ll}
\hline Free laccase & $0.0194 \pm 5.03 .10^{-4}$ \\
PA6-L & $0.0189 \pm 5.4 .10^{-4}$ \\
PA6Fe-L & $0.0193 \pm 7.89 .10^{-4}$ \\
PA6FeP-L & $0.0203 \pm 7.57 .10^{-4}$ \\
PA6Fe $_{3} \mathrm{O}_{4}-\mathrm{L}$ & $0.0165 \pm 8.11 .10^{-4}$
\end{tabular}

Figure 10. Kinetics of the enzymatic catechol oxidation by: (a) Free laccase; (b) PA6FeP-L conjugate; (c) absorbance time dependence plot $A_{\max }^{410}=f(t)$ for all samples during the first $2 \mathrm{~h}$ of oxidation; (d) visualization of the color evolution in a catechol oxidation experiment and the rate constants for all laccase samples studied.

It should be noted that the dependencies in Figure 10c are linear only up to 45-60 min of oxidation time for all samples. From this point on, linearity is maintained only with the native laccase, while with all PA6@L conjugates, a curvature appears. This apparent delay of the quinone formation is most probably caused by the adsorption of quinonoid compounds upon the PA6 MP carriers. In fact, this adsorption starts from the beginning of the catechol transformation, but it becomes more pronounced after 45 min reaction time. As seen from the images in Figure 10d, the microparticulate PA6@L conjugates become darker and after $3 \mathrm{~h}$ reaction time they are completely black. This can be attributed to the formation of highly conjugated $o$-benzoquinone imines (Schiff-bases) chemically bound on the polyamide MP surface [59]. 
Figure $10 \mathrm{~d}$ also visualizes the attraction of the Fe-containing conjugates by constant magnets, which is an advantage that enhances their easy and complete removal from the reaction mixture and repeated reuse. Therefore, all PA6@L samples were removed from their supernatants after the first $3 \mathrm{~h}$ cycle, washed with methanol so as to free the surface of the MP carriers, and were subsequently reused for oxidation of fresh catechol aliquots, performing five cycles of $3 \mathrm{~h}$ altogether. The rate constants of the enzymatic reaction were calculated for each cycle from the slope of the kinetic dependence (Table 5) also showing the visual aspect of the supernatants at each stage. Significant enzymatic oxidation of catechol is registered in each of the five cycles of PA6@L utilization. As expected, these rate constants were the highest during the first cycle, then they decreased to $42-45 \%$ during the second cycle and reached finally $22-27 \%$ of the initial values during the fifth cycle. Interestingly, the type of magnetic filler has some influence upon the conjugate's activity only during the first cycle, after which all systems display similar oxidation activity.

Table 5. Rate constants and visual aspects of the supernatants after five enzymatic oxidation cycles with PA6@L conjugates and free laccase.

\begin{tabular}{|c|c|c|c|}
\hline $\begin{array}{c}\text { Oxidation } \\
\text { Cycle }\end{array}$ & Sample & $\begin{array}{c}\text { Enzymatic Catechol } \\
\text { Oxidation Rate } \\
\text { Constant, } \\
k, \min ^{-1}\end{array}$ & $\begin{array}{c}\text { Visual Representation of } 5 \\
\text { Consecutive Catechol } \\
\text { Oxidation Cycles }\end{array}$ \\
\hline \multirow{4}{*}{5} & PA6-L & $0.0043 \pm 2.69 .10^{-4}$ & \\
\hline & PA6Fe-L & $0.0042 \pm 1.89 .10^{-4}$ & \\
\hline & PA6FeP-L & $0.0045 \pm 1.32 .10^{-4}$ & \\
\hline & $\mathrm{PA}_{6} \mathrm{Fe}_{3} \mathrm{O}_{4}-\mathrm{L}$ & $0.0044 \pm 2.01 .10^{-4}$ & \\
\hline \multirow{4}{*}{4} & PA6-L & $0.0046 \pm 7.88 .10^{-5}$ & \\
\hline & PA6Fe-L & $0.0050 \pm 9.61 .10^{-5}$ & \\
\hline & PA6FeP-L & $0.0061 \pm 3.50 .10^{-4}$ & \\
\hline & $\mathrm{PA}_{6} \mathrm{Fe}_{3} \mathrm{O}_{4}-\mathrm{L}$ & $0.0050 \pm 9.66 .10^{-5}$ & \\
\hline \multirow{4}{*}{3} & PA6-L & $0.0061 \pm 7.31 .10^{-5}$ & \\
\hline & PA6Fe-L & $0.0051 \pm 9.37 .10^{-5}$ & \\
\hline & PA6FeP-L & $0.0069 \pm 2.35 .10^{-4}$ & \\
\hline & $\mathrm{PA}_{6} \mathrm{Fe}_{3} \mathrm{O}_{4}-\mathrm{L}$ & $0.0051 \pm 1.58 .10^{-4}$ & \\
\hline \multirow{4}{*}{2} & PA6-L & $0.0085 \pm 3.81 .10^{-4}$ & \\
\hline & PA6Fe-L & $0.0082 \pm 3.87 .10^{-4}$ & \\
\hline & PA6FeP-L & $0.0086 \pm 2.16 .10^{-4}$ & \\
\hline & $\mathrm{PA}_{6} \mathrm{Fe}_{3} \mathrm{O}_{4}-\mathrm{L}$ & $0.0071 \pm 1.23 .10^{-4}$ & \\
\hline \multirow{4}{*}{1} & PA6-L & $0.0189 \pm 5.44 .10^{-4}$ & \\
\hline & PA6Fe-L & $0.0193 \pm 7.82 .10^{-4}$ & \\
\hline & PA6FeP-L & $0.0203 \pm 7.57 .10^{-4}$ & \\
\hline & $\mathrm{PA}_{6} \mathrm{Fe}_{3} \mathrm{O}_{4}-\mathrm{L}$ & $0.0165 \pm 1.58 .10^{-4}$ & \\
\hline - & Free Laccase & $0.0194 \pm 7.82 .10^{-4}$ & \\
\hline
\end{tabular}

\subsection{Structure of Polycatechol Products}

Theoretically, the polymerization of catechol will be accompanied by a clear change of the free phenolic $\mathrm{OH}$ group concentration in reaction medium. Expectedly, the initial solution of catechol before oxidation by native laccase or by PA6@L conjugates does not show any absorption at $410 \mathrm{~nm}$ for quinonoid compounds. As seen from Figure 10a-c, some benzoquinone amounts appear after $15 \mathrm{~min}$ of enzyme-mediated oxidation that increase almost linearly during the first $3 \mathrm{~h}$ of the process. After $24 \mathrm{~h}$ of reaction, however, the quinone absorption peak either disappears completely (Figure 10a), or significantly decreases in intensity (Figure 10b). This can be due to the fact that the first enzymatic stage of oxidation to benzoquinone was completed and the non-catalytic polymerization of the latter to polycatechol has started. As indicated by Su et al. [26], both processes of catechol transformation are accompanied by a decrease in the free phenolic $\mathrm{OH}$ groups in the system that can be quantified by the Folin-Ciocalteu method [60]. Therefore, we followed the evolution of the free $\mathrm{OH}$-group content in the oxidation processes during all consecutive 
cycles catalyzed by PA6@L conjugates and in one cycle mediated by free laccase. In doing so, the supernatants after $3 \mathrm{~h}$ process and the DMSO-soluble solid products after the fifth cycle were analyzed (Table 6).

Table 6. Determination of free phenolic OH groups.

\begin{tabular}{|c|c|c|c|c|c|}
\hline & Sample & $\begin{array}{c}\text { Absorbance } \\
\text { at } 750 \mathrm{~nm}\end{array}$ & $\begin{array}{c}\text { Free } \mathrm{OH} \text {, a.u. } \\
\text { Gallic acid }\end{array}$ & $\begin{array}{c}\text { Free OH } \\
\mu \mathrm{mol} \\
\text { Catechol }\end{array}$ & $\begin{array}{l}\text { Free OH } \\
\text { Group } \\
\text { Retention }\end{array}$ \\
\hline \multicolumn{2}{|c|}{ Catechol $20 \mathrm{~mL} 25 \mathrm{mM}$} & 0.450 & 518.102 & 0.0250 & 100.0 \\
\hline \multicolumn{2}{|c|}{ Free laccase } & 0.148 & 148.963 & 0.0072 & 28.8 \\
\hline \multirow{4}{*}{ I cycle } & PA6-L & 0.242 & 263.861 & 0.0127 & 50.9 \\
\hline & PA6Fe-L & 0.254 & 278.529 & 0.0134 & 53.8 \\
\hline & PA6FeP-L & 0.204 & 217.413 & 0.0105 & 42.0 \\
\hline & $\mathrm{PA}_{6} \mathrm{Fe}_{3} \mathrm{O}_{4}-\mathrm{L}$ & 0.241 & 262.638 & 0.0127 & 50.7 \\
\hline \multirow{4}{*}{ II cycle } & PA6-L & 0.291 & 323.754 & 0.0156 & 62.5 \\
\hline & PA6Fe-L & 0.335 & 377.536 & 0.0182 & 72.9 \\
\hline & PA6FeP-L & 0.289 & 321.309 & 0.0155 & 62.0 \\
\hline & $\mathrm{PA}_{6} \mathrm{Fe}_{3} \mathrm{O}_{4}-\mathrm{L}$ & 0.386 & 439.874 & 0.0212 & 84.9 \\
\hline \multirow{4}{*}{ III cycle } & PA6-L & 0.358 & 405.649 & 0.0196 & 78.3 \\
\hline & PA6Fe-L & 0.369 & 419.095 & 0.0202 & 80.9 \\
\hline & PA6FeP-L & 0.309 & 345.756 & 0.0167 & 66.7 \\
\hline & $\mathrm{PA}_{6} \mathrm{Fe}_{3} \mathrm{O}_{4}-\mathrm{L}$ & 0.405 & 463.098 & 0.0223 & 89.4 \\
\hline \multirow{4}{*}{ IV cycle } & PA6-L & 0.364 & 412.983 & 0.0199 & 79.7 \\
\hline & PA6Fe-L & 0.376 & 427.651 & 0.0206 & 82.5 \\
\hline & PA6FeP-L & 0.316 & 354.312 & 0.0171 & 68.4 \\
\hline & $\mathrm{PA}_{6} \mathrm{Fe}_{3} \mathrm{O}_{4}-\mathrm{L}$ & 0.378 & 430.095 & 0.0208 & 83.0 \\
\hline \multirow{4}{*}{ V cycle } & PA6-L & 0.371 & 421.539 & 0.0203 & 81.4 \\
\hline & PA6Fe-L & 0.385 & 438.652 & 0.0212 & 84.7 \\
\hline & PA6FeP-L & 0.324 & 364.090 & 0.0176 & 70.3 \\
\hline & $\mathrm{PA}_{6} \mathrm{Fe}_{3} \mathrm{O}_{4}-\mathrm{L}$ & 0.396 & 452.097 & 0.0218 & 87.3 \\
\hline \multirow{5}{*}{$\begin{array}{l}\text { Solid residue } \\
\text { after cycle V }\end{array}$} & Free laccase * & 0.085 & 71.958 & 0.0035 & 13.9 \\
\hline & PA6-L & 0.035 & 23.278 & 0.0011 & 4.5 \\
\hline & PA6Fe-L & 0.023 & 9.027 & 0.0004 & 1.7 \\
\hline & PA6FeP-L & 0.016 & 0.119 & 0.0001 & 0.0 \\
\hline & $\mathrm{PA}_{6} \mathrm{Fe}_{3} \mathrm{O}_{4}-\mathrm{L}$ & 0.270 & 13.777 & 0.0007 & 2.7 \\
\hline
\end{tabular}

Note: ${ }^{*}$ In this case the solid residue is after one cycle and contains only dark brown powder product. In all other cases the solid residue represents the PA6@L microparticulate conjugates covered by black polycatechol products. The linear regression for cycles I-V is: $y=8.1812 .10^{-4} \cdot x+0.02613$; The linear regression for the $\mathrm{OH}$ groups determination in the solid residue after Cycle $\mathrm{V}$ is: $y=8 \cdot 42 \cdot 10^{-4} \cdot x+0.054$.

The concentration of phenolic $\mathrm{OH}$ groups in the starting catechol solution was considered $100 \%$. In the oxidation with free laccase, after three hours, the supernatant lost about $71 \%$ of the free $\mathrm{OH}$ groups due formation of benzoquinone. Working with PA6@L conjugates led to a lesser percent of $\mathrm{OH}$ group loss-from $58 \%$ for the PA6FeP-L sample to $46 \%$ for PA6Fe-L. During the second, third, and fourth oxidation cycles the fraction of oxidized catechol $\mathrm{OH}$ groups was in the range of $15-38 \%, 10-33 \%$, and $17-31 \%$, respectively. The last oxidation cycle resulted in $13-30 \%$ elimination of phenolic $\mathrm{OH}$ groups. The results are in agreement with the kinetic data showing that the oxidation rate is the 
highest in the beginning and decreases after each consecutive oxidation cycle. This can be seen in the photograph in Table 5 visualizing the color change in the supernatants after each cycle. In all cases, the best-performing immobilized laccase conjugate was PA6FeP-L, i.e., the conjugate with the largest amount of highly densified laccase and showing the highest activity.

Studying, in a similar way, the DMSO-soluble dark-brown solid product after $24 \mathrm{~h}$ of oxidation by free laccase displayed $14 \%$ of residual phenolic $\mathrm{OH}$ groups. The fact that this product was insoluble in the aqueous buffer solution suggests that most probably polycatechol was formed. According to the MALDI-TOF structural studies of $\mathrm{Su}$ et al. [61], the smaller the total content of free $\mathrm{OH}$ groups, the higher the molecular weight of polycatechol formed.

The solid residue after the fifth cycle of PA6@L-mediated catechol oxidation represents PA6 support microparticles covered by polycatechol products. The test for free phenolic $\mathrm{OH}$ groups showed very low residual concentration in these DMSO extracts, not exceeding $3.0-4.5 \%$, the concentration in PA6FeP being virtually zero (Table 6). This observation suggests relatively high molecular weight of the polycatechol formed, which was confirmed by our thermal characterization by DSC and TGA.

Figure 11 displays the DSC scans in heating and cooling modes of the PA6 and PA6-L samples, as well as of the solid product obtained with PA6-L catalyst from catechol (PA6-LPolycat) after the fifth oxidation cycle. In the same figure, the thermograms of the solid material prepared with free laccase (Free Lacc-Polycat) are also presented.
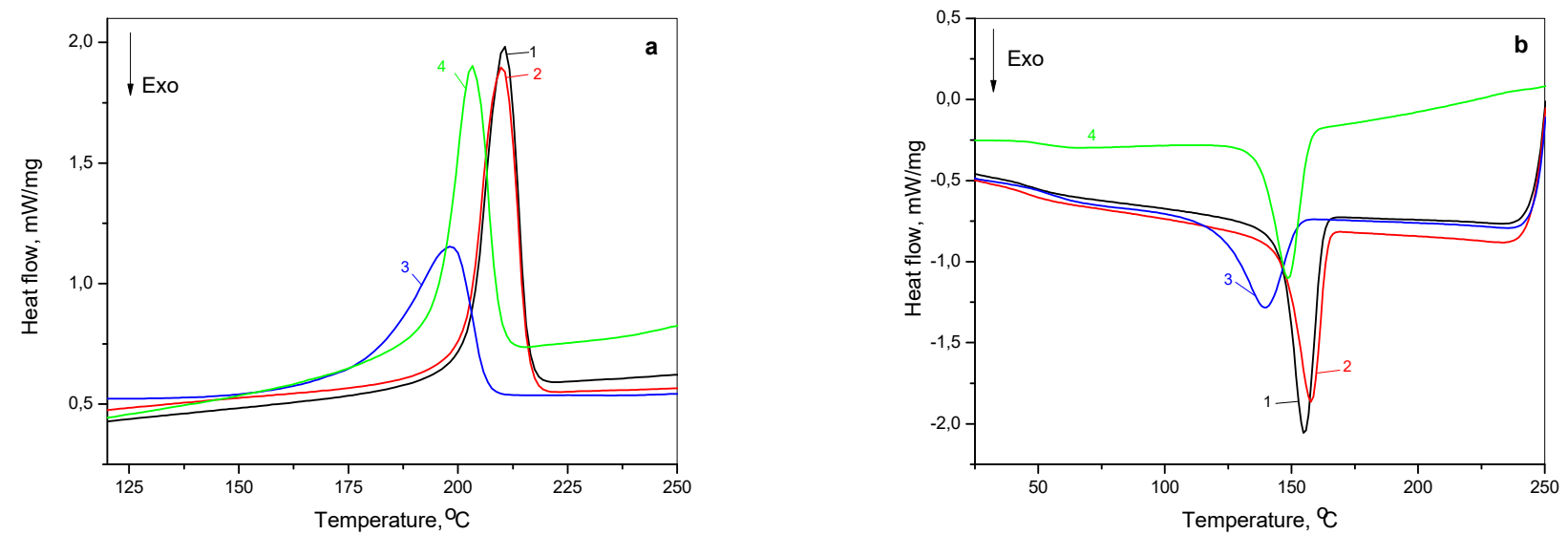

Figure 11. DSC scans in heating (a) and cooling (b) modes of 1-PA6; 2-PA6-L; 3-PA6-L-Polycat; 4-Free Lacc-Polycat obtained after $24 \mathrm{~h}$.

The Free-Lacc-Polycat (trace 4 in Figure 11) is a semcrystalline polymer material with a melting temperature of $203{ }^{\circ} \mathrm{C}$ that crystallizes at $148^{\circ} \mathrm{C}$ when cooling at $10{ }^{\circ} \mathrm{C} / \mathrm{min}$. This thermal behavior is distinct from that of the neat PA6 support (trace 1) and the PA6-L conjugate before using it as a catalyst (trace 2). They both melt at $210^{\circ} \mathrm{C}$ and crystallize in the $154-157^{\circ} \mathrm{C}$ interval. The PA6-L-Polycat sample (trace 3) shows a broad melting peak at $198^{\circ} \mathrm{C}$ during the heating scan and, in cooling mode, a crystallization exotherm at $139^{\circ} \mathrm{C}$. These single melting and crystallization peaks suggest co-crystallization of the PA6 support and the polycatechol formed upon its surface.

The fact that the polycatechol products are accumulated upon the PA6 support is confirmed by the TGA traces in Figure S5 of the Supporting Information. Thus, the PA6-LPolycat sample displays circa $8 \%$ of carbonized residue at $550{ }^{\circ} \mathrm{C}$. This value is very close to the sum of the residues of the PA6-L sample $(3.8 \%)$ and of the solid product obtained with free laccase $(3.8 \%)$.

To elucidate the structure of the polymeric products of catechol oxidation, ${ }^{1} \mathrm{H}$ NMR spectroscopy was employed with the solid residue of the supernatants after the first oxidation cycle with PA6-L. As seen from Table 6, half of the initial free $\mathrm{OH}$ groups 
disappear due to the formation of polymer products. It can therefore be hypothesized that the protons of the residual hydroxyl groups are extensively involved in a strong hydrogen bonding along the polymer backbone in accordance with the structure of the predominantly ortho-ortho linked repeat units (Figure 12).

2 PA6 - L MeOD
600 MHz

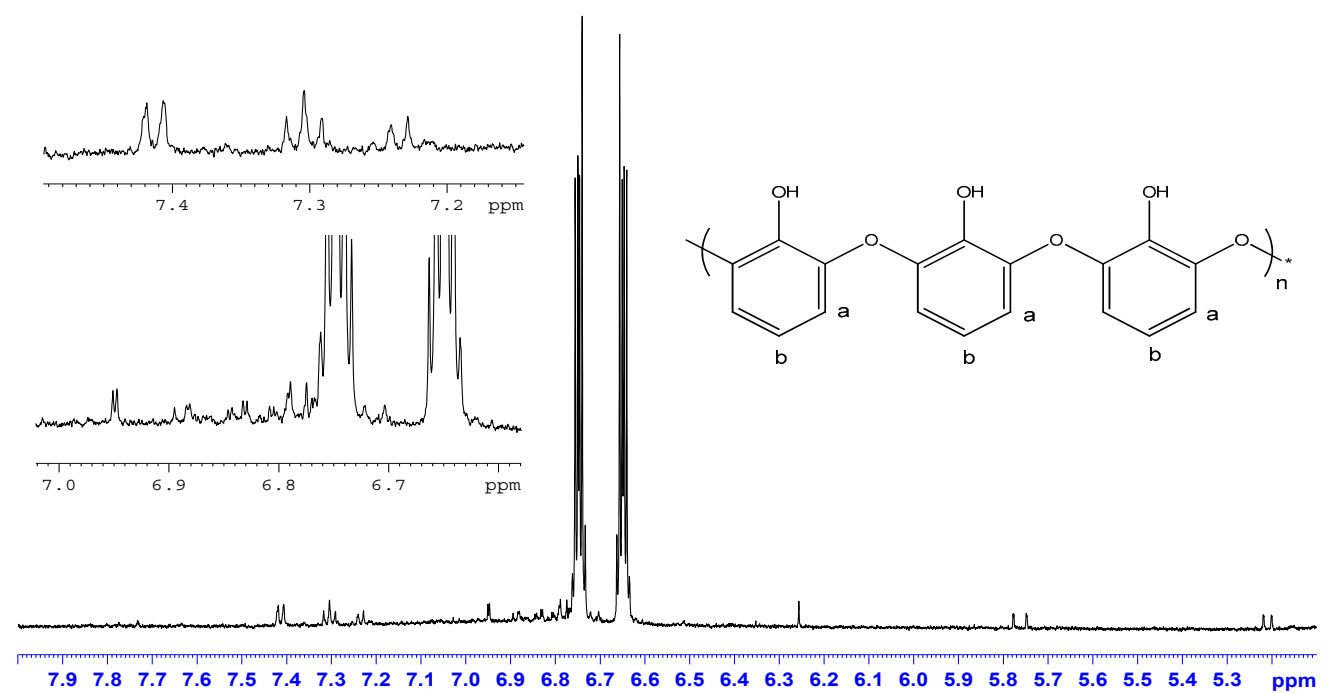

Figure 12. Expanded ${ }^{1} \mathrm{H}$ NMR spectrum of the solid residue after the first oxidation cycle of catechol. Polymerization mediated by PA6-L. Solvent $\mathrm{CH}_{3} \mathrm{OD}$, room temperature, $600 \mathrm{MHz}$.

In notable distinction to previously reported structural studies of polycatechol oligomers [62], the aromatic region of the ${ }^{1} \mathrm{H}$ NMR spectra is rather complex. The strong signals centered at $6.64 \mathrm{ppm}$ and $6.73 \mathrm{ppm}$ could be assigned to the meta-(a) and para (b) protons in the repeating units (see structure in Figure 12). The fact that these signals are not doublets indicates that other similar structures are also present, and their characteristic signals overlap (see for example the structure in the graphical abstract). The weak peaks at $6.78 \mathrm{ppm}$ and $6.84 \mathrm{ppm}$ indicate the presence of catechol monomer and the signals in the 7.2-7.5 ppm region might be caused by small amounts of low molecular weight structures formed through C-C coupling of the initial catechol radicals (Figure 13).

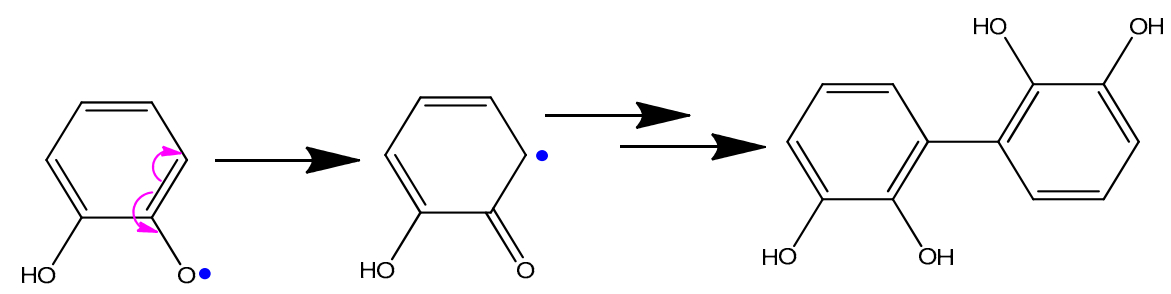

Figure 13. Tentative repeating unit structure resulting from C-C coupling of catechol radicals formed in the initial stages of PA6@L mediated polymerization.

The lack of signals characteristic of $\mathrm{OH}$ groups could be explained by the previously mentioned hydrogen bond interactions along the oligomer/polymer chains and the fast deuterium-proton exchange with the NMR solvent.

\section{Materials and Methods}

\subsection{Materials}

The 2PD functional monomer for the PA4 synthesis and all solvents used in this work are of analytical grade and were supplied by Sigma Aldrich, Portugal. The laccase from 
Trametes versicolor $(\geq 0.5 \mathrm{U} / \mathrm{mg})$ was also purchased from Sigma-Aldrich and used without further purification. As activator of the anionic polymerization of ECL the commercial product Brüggolen C20 from Brüggemann Chemical (Germany) was employed containing, according to the manufacturer, $80 \mathrm{wt} \%$ of aliphatic diisocyanate blocked in $\varepsilon$-caprolactam. The polymerization initiator sodium dicaprolactamato-bis-(2-methoxyethoxo)-aluminate (Dilactamate, DL), which is also a commercial product was supplied by Katchem (Czech Republic) and used without further treatment. Soft, non-insulated iron particles (Fe content $>99.8 \%$ ), with average diameters of 3-5 $\mu \mathrm{m}$ were kindly donated by the manufacturer BASF, Ludwigshafen, Germany. The $\mathrm{Fe}_{3} \mathrm{O}_{4}$ magnetic particles are a product of Sigma-Aldrich with $>99 \%$ purity and grain sizes of $50-80 \mathrm{~nm}$. Diammonium 2,2'-azinobis(3-ethylbenzothiazoline-6-sulfonate) (ABTS) with a purity of $\geq 98 \%$ (HPLC), as well as malachite green and bromophenol blue dyes were purchased from Sigma-Aldrich, Portugal. All buffer solutions in this work were prepared with DDW.

\subsection{Instrumentation and Methods}

Fourier-transform infra-red spectroscopy with attenuated total reflection (FTIR-ATR). The FTIR-ATR spectra were collected in a Perkin-Elmer Spectrum 100 apparatus using a horizontal ATR attachment with ZnSe crystal. Spectra were acquired between 4000 and $600 \mathrm{~cm}^{-1}$ accumulating up to 16 spectra with a resolution of $2 \mathrm{~cm}^{-1}$. The PA4 samples were studied in the form of fine powders.

Ultraviolet-Visible spectroscopy (UV-VIS). The UV-VIS analysis was performed on a Shimadzu UV-2501 PC spectrometer. The absorbance at $\lambda=286 \mathrm{~nm}$ of the aqueous solutions after immobilization, placed in quartz cuvettes, was measured to determine the protein content and calculate the immobilization efficiency (IE). The assessment of the laccase activity was performed using ABTS as substrate measuring the absorbance at $\lambda=414 \mathrm{~nm}$ as previously indicated by Claus et al. [19]. One unit of laccase activity expressed in $\mu$ katals corresponds to the amount of enzyme transforming $1 \mu \mathrm{mol}$ ABTS per second at $\mathrm{pH} 4$ and $25{ }^{\circ} \mathrm{C}$. The kinetics of catechol oxidation was monitored by measuring the absorption maxima at $410 \mathrm{~nm}$ and the absorbance at $\lambda=750 \mathrm{~nm}$ was used for the assessment of the total content of free $\mathrm{OH}$ groups.

Scanning electron microscopy (SEM). The SEM studies were performed in a NanoSEM200 apparatus of FEI Nova using mixed secondary electron/back-scattered electron in-lens detection. The pulverulent samples were observed after sputter-coating with $\mathrm{Au} / \mathrm{Pd}$ alloy in a 208 HR equipment of Cressington Scientific Instruments with high-resolution thickness control.

Thermo-gravimetric analysis (TGA). The real iron load, $R_{L}$, in the magnetic responsive PA6 micro-particulate supports was established by means of thermo-gravimetric analysis (TGA) in a Q500 gravimetric balance (TA Instruments), heating the samples in the $40-600{ }^{\circ} \mathrm{C}$ range at $20^{\circ} \mathrm{C} / \mathrm{min}$ in inert atmosphere. The $R_{L}$ was calculated according to:

$$
R_{L}=\left(R_{i}-R_{P A 6}\right) \times 100,[\%]
$$

where $R_{\text {PA6 }}$ is the carbonized residue at $600{ }^{\circ} \mathrm{C}$ of the neat PA6 particles and $R_{i}$ represents the carbonized residue of the respective $\mathrm{Fe}-$ or $\mathrm{Fe}_{3} \mathrm{O}_{4}$ - containing PA6 MP.

Differential scanning calorimetry (DSC). The DSC measurements were carried out in a $200 \mathrm{~F} 3$ equipment of Netzsch at a heating/cooling rate of $10^{\circ} \mathrm{C} / \mathrm{min}$ under nitrogen purge. The samples were heated to $260{ }^{\circ} \mathrm{C}$, cooled down to $0{ }^{\circ} \mathrm{C}$, and then heated back to $260{ }^{\circ} \mathrm{C}$. The typical sample weights were in the 10 to $15 \mathrm{mg}$ range.

Synchrotron X-ray studies. Synchrotron wide- (WAXS) and small-angle X-ray scattering (SAXS) measurements were performed in the NCD-SWEET beamline of the ALBA synchrotron facility in Barcelona, Spain [63]. Two-dimensional detectors were used, namely LH255-HS (Rayonix, Evanston, IL, USA) and Pilatus 1M (Dectris, Switzerland) for registering the WAXS and SAXS patterns, respectively. The sample-to-detector distance was set to $150.3 \mathrm{~mm}$ for WAXS and $2696.5 \mathrm{~mm}$ for SAXS measurements, the $\lambda$ of the incident beam being $0.1 \mathrm{~nm}$ and the beam size $0.35 \times 0.38 \mathrm{~mm}(\mathrm{~h} \times \mathrm{v})$. The $2 \mathrm{D}$ data from the two detectors 
were reduced to 1D data using pyFAI software [64]. For further processing of the WAXS and SAXS patterns the commercial package Peakfit 4.12 by SeaSolve was implemented.

NMR analyses. The NMR analyses of the polymerization mixtures were performed in methanol-d on a Bruker Avance $600 \mathrm{MHz}$ instrument at room temperature.

\subsection{Sample Preparation and Activity Testing}

\subsubsection{Synthesis of Empty or Magnetic PA6 Microparticulate Supports}

The PA6 MP supports were synthesized by AAROP as previously described by Dencheva et al. [39]. In a typical synthesis, $0.2 \mathrm{M}$ of ECL was added to $150 \mathrm{~mL}$ of a mixed hydrocarbon solvent (toluene/xylene 1:1 by volume) while stirring, under nitrogen atmosphere, refluxing the reaction mixture for 10-15 $\mathrm{min}$. In the magnetic responsive supports, $3 \mathrm{wt} \%$ of the respective ferromagnetic filler were added at this stage. Subsequently, $3.0 \mathrm{~mol} \%$ of DL and $1.5 \mathrm{~mol} \%$ of C20 were introduced. The reaction time was always $2 \mathrm{~h}$ (from the point of catalytic system addition) and the temperature was maintained in the $125-135^{\circ} \mathrm{C}$ range, at a constant stirring of about $800 \mathrm{rpm}$. The PA6 supports formed as fine powders and were separated from the reaction mixture by hot vacuum filtration, washed several times with methanol for elimination of unreacted monomer and dried in a vacuum oven at $60{ }^{\circ} \mathrm{C}$. To remove the low-molecular weight PA6 fraction, Soxhlet extraction with methanol for $4 \mathrm{~h}$ was applied. Altogether four PA6 supports were synthesized: PA6, PA6Fe, $\mathrm{PA} 6 \mathrm{FeP}$, and $\mathrm{PA}_{6 \mathrm{Fe}} \mathrm{O}_{4}$.

\subsubsection{Immobilization of Laccase by Physical Adsorption}

A typical immobilization was carried out by first preparing the laccase solution in DDW with concentration of $2 \mathrm{mg} / \mathrm{mL}$. Five hundred milligrams of each PA6 support were introduced into $8 \mathrm{~mL}$ of this laccase solution and the four sample tubes were incubated at $37^{\circ} \mathrm{C}$ for $24 \mathrm{~h}$ using a laboratory orbital shaker. Thereafter, the samples were centrifuged, the supernatant was decanted, and the laccase-immobilized PA6@L samples were washed two times with distilled water to remove the non-adsorbed laccase. UV analysis of the supernatants was performed to determine the residual laccase and calculate the immobilization efficiency, IE, expressed as:

$$
I E=\frac{C_{0}-C_{s}}{C_{0}} \times 100, \%
$$

where $C_{0}$ is the starting laccase concentration and $C_{s}$ is the laccase content in the resultant supernatant after completion of the immobilization process. To calculate $C_{s}$, the absorbance at $\lambda=286 \mathrm{~nm}$ characteristic for the proteic part of the enzyme was measured and the laccase concentration was determined using a standard calibration plot. This direct UV method provided the most reliable data with the highest reproducibility and the lowest standard deviation between the individual measurements being in the range of the 3-5\%. The indirect Bradford and bicinchoninic acid colorimetric assays produced data dispersions of up to $15 \%$ and $30 \%$, respectively. Altogether, four samples of laccase immobilized by adsorption on PA6 MP were prepared and designated as PA6-L, PA6Fe-L, PA6FeP-L, and $\mathrm{PA}_{6} \mathrm{Fe}_{3} \mathrm{O}_{4}$-L; generic name PA6@L. They were stored in semi-dry conditions at $4{ }^{\circ} \mathrm{C}$. The basic characteristics of the PA6@L samples are listed in Table 2.

\subsubsection{Laccase Activity Assay}

Native laccase and all conjugates of laccase-immobilized PA6@L were assayed for their activities using ABTS as a color-generating substrate. The rate of the formation of ABTS-cation radical $\left(\mathrm{ABTS}^{+\cdot}\right)$ due to the catalytic action of laccase was proportional to the enzyme activity. In a typical assay of free laccase, $0.06 \mathrm{~mL}$ of the enzyme solution $(2.0 \mathrm{mg} / \mathrm{mL}$ in $25 \mathrm{mM}$ citrate buffer, $\mathrm{CB}, \mathrm{pH} 4)$ and $0.84 \mathrm{~mL}$ of the same $\mathrm{CB}$ were introduced into the spectrometer cell, followed by $0.1 \mathrm{~mL}$ of freshly prepared $5 \mathrm{mM}$ solution of ABTS in DDW. During the next $60 \mathrm{~s}$ the absorbance at $414 \mathrm{~nm}\left(\varepsilon_{414}=36,000 \mathrm{M}^{-1} . \mathrm{cm}^{-1}\right)$ was measured every $1 \mathrm{~s}$. To determine the activity of the PA6@L conjugates, $5 \mathrm{mg}$ of each 
sample were placed directly into the UV cuvette, adding $1.0 \mathrm{~mL}$ of $25 \mathrm{mM} \mathrm{CB}, \mathrm{pH} 5$ and $0.1 \mathrm{~mL}$ of ABTS solution. Then, the absorbance at $414 \mathrm{~nm}$ was measured each second during $1 \mathrm{~min}$.

In all tests, the enzyme activities were expressed in microkatals. One microkatal of enzyme activity ( $\mu \mathrm{kat}$ ) was defined as the amount of enzyme that converted $1.0 \mu \mathrm{mol}$ of ABTS to ABTS ${ }^{+\cdot}$ per second, at $\mathrm{pH} 4$ and $25^{\circ} \mathrm{C}$. The enzyme activity assay was always performed in duplicate, and the standard deviations in measurements were consistently below $3 \%$. Throughout this study, enzyme activities are expressed in $\mu$ kat per liter $\left(\mu \mathrm{kat} . \mathrm{L}^{-1}\right)$. Table 4 contains the data of PA6@L activity (ABTS substrate). The specific activity was calculated by normalizing the activity per $1 \mathrm{mg}$ of enzyme. The relative activity of PA6@L in percentage was determined as a relation to the activity of the free laccase taken as $100 \%$.

\subsubsection{Determination of the Kinetics Parameters of the Enzymatic Oxidation}

Kinetic tests were carried out at room temperature in $20 \mathrm{mM}$ citrate buffer, $\mathrm{pH} 4$, using ABTS as a substrate and varying the substrate concentration from 0.2 to $1 \mathrm{mM}$. Free laccase and all PA6@L conjugates were studied. The kinetics parameters $K_{m}$ and $V_{\max }$ were determined according to the Lineweaver-Burk double reciprocal model, as follows:

$$
\frac{1}{V_{0}}=\frac{K_{m}}{V_{\max }} \cdot \frac{1}{S}+\frac{1}{V_{\max }}
$$

where $V_{0}$ is the initial catalytic rate and $S$ is the substrate concentration.

\subsubsection{Kinetics of Enzymatic Oxidation of Catechol by Laccase-Immobilized PA6@L}

The enzymatic oxidation of catechol was performed directly in the cuvette for UVVIS monitoring of the process. Thus, $20 \mathrm{mg}$ of wet PA6@L particles loaded with about 2.6-3.0 nkat/mL laccase were introduced into the cuvette. Then $1 \mathrm{~mL}$ of $25 \mathrm{mM}$ catechol solution in citrate buffer ( $\mathrm{pH} \mathrm{4}, 20 \mathrm{mM}$ ) were added. Every 5 min full UV-VIS spectrum was taken measuring the intensity of the absorption maxima at $410 \mathrm{~nm}$. After $3 \mathrm{~h}$ the supernatant was decanted and guarded for further studies. The PA6@L particles after this first catalytic cycle were washed three times with $1 \mathrm{~mL}$ methanol to extract the soluble oxidized catechol products deposited on the MP surface and were then subjected to second oxidative cycle by adding a new portion of $1 \mathrm{~mL}$ catechol solution. Thus, the reusability of all four PA6@L conjugates for enzymatic catechol oxidation was evaluated during five consecutive cycles. As a control, catechol oxidation with free laccase was also performed once at the same conditions.

\subsubsection{Determination of the Total Content of Free OH Groups}

The initial catechol solution, the supernatants from every oxidative cycle, and the solid products after the last fifth cycle were analyzed for total content of free phenolic $\mathrm{OH}$ groups using the Folin-Ciocalteu spectrophotometric method [65]. Thus, $40 \mu \mathrm{L}$ of the liquid sample (initial catechol solution or supernatants) were mixed with $800 \mu \mathrm{L} 10$-fold diluted Folin-Ciocalteu reagent in an Eppendorf self-locked tube. After 2-3 min, $800 \mu \mathrm{L}$ of $7 \% \mathrm{w} / \mathrm{v}$ sodium carbonate aqueous solution were added under stirring and the volume in the tube was adjusted to $2 \mathrm{~mL}$ by adding $360 \mu \mathrm{L}$ double distilled water. After $1 \mathrm{~h}$ at room temperature, the absorbance at $750 \mathrm{~nm}$ was measured against blank in a UV-VIS spectrophotometer. In the case of the solid materials obtained with free laccase after $24 \mathrm{~h}$ and after the fifth cycle with all PA6@L samples, $3 \mathrm{mg}$ of each of these solids were taken and dissolved in $40 \mu \mathrm{L} \mathrm{DMSO}$, adding thereafter the same amounts and types of reagents as in the previous sample series. The total content of free $\mathrm{OH}$ groups was assessed by plotting a calibration curve with gallic acid (from $100 \mathrm{mM}$ to $1000 \mathrm{mM}$, with linear regression coefficient $\left.\mathrm{r}^{2}=0.99875\right)$. The consolidated data on free phenolic $\mathrm{OH}$ groups are presented in Table 6. 


\section{Conclusions}

This is the first report on catechol transformations mediated by Trametes versicolor laccase immobilized on PA6 supports. It differs from the previous study on PA4-based laccase conjugates [43] in several crucial aspects. The PA6 microparticulate supports were synthesized by AAROP at $120^{\circ} \mathrm{C}$ and atmospheric pressure, while for the PA4 supports temperatures as low as $40^{\circ} \mathrm{C}$ and vacuum were needed for the polymerization to produce microparticles. These differences in the reaction conditions resulted in different topography, morphology, and crystallization behavior of the particulate supports. Thus, the much porous PA6-based supports led to a laccase immobilization efficiency of 77-92\%, while with the PA4@L conjugates these values were lower, varying in the 53-81\% range. Moreover, the relative laccase activity of the PA6@L conjugates reached 106\%, i.e., some of them were more active than the native laccase itself at the same reaction conditions. Meanwhile, the maximum relative activity of the PA4-laccase conjugates did not exceed $60 \%$. Another important difference is that in the study of the PA4-laccase conjugates, two different immobilization techniques were applied-physical adsorption after, and entrapment during the AAROP. The latter technique is impossible with the PA6 supports. All these findings suggest different but possibly complementary applications of the two types of laccase conjugates, which, in our opinion, justifies their detailed investigation.

All PA6@L complexes of this study were characterized by IR spectroscopy and synchrotron WAXS/SAXS analyses. It was shown that the enzymatic activity was promoted by the presence of iron cores (regular and phosphate-coated $\mathrm{Fe}^{0}$ ) in the microparticles, as compared to the native free laccase. All PA6@L conjugates were able to mediate the transformation of catechol over up to five repeating cycles. The resulting reaction mixtures have complex compositions as revealed by NMR spectroscopy. More importantly, the majority of them are not soluble in aqueous media, a good proof of concept for the applicability of these new systems for detoxification of wastewater streams.

Supplementary Materials: The following materials are available online at https://www.mdpi. com/2073-4344/11/2/239/s1: Figure S1: Chemical reactions occurring during AAROP of ECL to PA6 microparticles; Figure S2: Histograms of the average size $\left(d_{\max }\right)$ and roundness $\left(d_{\max } / d_{\min }\right)$ distributions for PA6 MP supports based on optical microscopy; Figure S3: Histograms of the equivalent circular diameter $d_{\max }$ and roundness $\left(d_{\max } / d_{\min }\right)$ distirbutions for PA6@L conjugates; Figure S4-Magnetization curves of neat supports and Fe filler; Figure 5-TGA traces; Figures S6-S9 A block of NMR data; Table S1: zeta potential values of empty particulate PA6-based supports; Table S2: Data from BET for the empty PA6 supports.

Author Contributions: Conceptualization, N.D. and Z.D.; data curation, N.D., S.O., and J.B.; formal analysis, N.D., S.O., J.B., and Z.D.; funding acquisition, Z.D., N.D., and I.G.; investigation, N.D., S.O., J.B., D.G., and M.M.; methodology, N.D., Z.D., and I.G.; software, M.M.; supervision, Z.D. and I.G.; validation, N.D., M.M., and Z.D.; writing — original draft preparation, N.D. and Z.D.; writingreview and editing, I.G. and Z.D. All authors have read and agreed to the published version of the manuscript.

Funding: The authors gratefully acknowledge the financial support of the project TSSiPRO NORTE01-0145-FEDER-000015, supported by the regional operation program NORTE2020, under the Portugal 2020 Partnership Agreement, through the European Regional Development Fund, as well as the support by National Funds through Fundação para a Ciência e Tecnologia (FCT), project UID/CTM/50025/2019. D.G. and I.G. wish to thank the Research Foundation of the State of New York-Networks of Excellence and the McIntyre-Stennis program of the US Department of Agriculture for partial funding. N.D. is also grateful for the personal program-contract CTTI-51/18-IPC.

Data Availability Statement: The data obtained by this study are included in this article and in the Supplementary Materials.

Conflicts of Interest: The authors declare no conflict of interest. The funders had no role in the design of the study, in the collection, analyses, or interpretation of data, in the writing of the manuscript, or in the decision to publish the results. 


\section{References}

1. Bull, A.T.; Bunch, A.W.; Robinson, G.K. Biocatalysts for clean industrial products and processes. Curr. Opin. Microbiol. 1999, 2, 246-251. [CrossRef]

2. Sheldon, R.A.; Van Rantwijk, F. Biocatalysis for sustainable organic synthesis. Aust. J. Chem. 2004, 57, 281-289. [CrossRef]

3. Durán, N.; Rosa, M.A.; D'Annibale, A.; Liliana Gianfreda, L. Applications of laccases and tyrosinases (phenoloxidases) immobilized on different supports: A review. Enzym. Microb. Technol. 2002, 31, 907-931. [CrossRef]

4. Ge, J.; Lu, D.; Liu, Z.; Liu, Z. Recent advances in nanostructured biocatalysts. Biochem. Eng. J. 2009, 44, 53-59. [CrossRef]

5. Hanefeld, U.; Gardossi, L.; Magner, E. Understanding enzyme immobilization. Chem. Soc. Rev. 2009, 38, 453-468. [CrossRef] [PubMed]

6. Hudson, S.; Magner, E.; Cooney, J.; Hodnett, B. Methodology for the immobilization of enzymes onto mesoporous materials. J. Phys. Chem. B 2005, 109, 19496-19506. [CrossRef] [PubMed]

7. Torres-Salas, P.; Monte-Martinez, A.; Cutiño-Avila, B.; Rodriguez-Colinas, B.; Alcalde, M.; Ballesteros, A.O.; Plou, F.J. Immobilized Biocatalysts-Novel approaches and tools for binding enzymes to supports. Adv. Mater. 2011, 23, 5275-5282. [CrossRef]

8. Sigurdardóttir, S.B.; Lehmann, J.; Ovtar, S.; Grivel, J.C.; Negra, M.; Kaiser, A.; Pinelo, M. Enzyme immobilization on inorganic surfaces for membrane reactor applications: Mass transfer challenges, enzyme leakage and reuse of materials. Adv. Synth. Catal. 2018, 360, 2578-2607. [CrossRef]

9. Shakya, A.K.; Nandakumar, K.S. An update on smart biocatalysts for industrial and biomedical applications. J. R. Soc. Interface 2018, 15, 20180062. [CrossRef]

10. Gitsov, I.; Hamzik, J.; Ryan, J.; Simonyan, A.; Nakas, J.P.; Omori, S.; Krastanov, A.; Cohen, T.; Tanenbaum, S.W. Enzymatic nanoreactors for environmentally benign biotransformations-1. Formation and catalytic activity of supramolecular complexes of laccase and linear-dendritic block copolymers. Biomacromolecules 2008, 9, 804-811. [CrossRef]

11. Scheibel, D.M.; Gitsov, I. Polymer-assisted biocatalysis: Effects of macromolecular architectures on the stability and catalytic activity of immobilized enzymes toward water-soluble and water-insoluble substrates. ACS Omega 2018, 3, 1700-1709. [CrossRef]

12. Mate, D.M.; Alcalde, M. Laccase: A multi-purpose biocatalyst at the forefront of biotechnology. Microb. Biotechnol. 2017, 10, 1457-1467. [CrossRef]

13. Couto, S.L.; Herrera, J.L. Lacasses in the textile industry. Biotechnol. Mol. Biol. Rev. 2006, 1, 115-120. Available online: https:/ /academicjournals.org/journal/BMBR/article-full-text-pdf/1C6FD3040214 (accessed on 20 October 2020).

14. Baldrian, P. Fungal laccases-Occurrence and properties. FEMS Microbiol. Rev. 2006, 30, 215-242. [CrossRef] [PubMed]

15. Scheibel, D.M.; Guo, D.; Luo, J.; Gitsov, I. A Single Enzyme Mediates the "Quasi-Living" Formation of Multiblock Copolymers with a Broad Biomedical Potential. Biomacromolecules 2020, 21, 2132-2146. [CrossRef] [PubMed]

16. Gitsov, I.; Wang, L.; Vladimirov, N.; Simonyan, A.; Kiemle, D.J.; Schütz, A. “Green” synthesis of unnatural poly(amino acid)s with zwitterionic character and $\mathrm{pH}$-responsive solution behavior, mediated by linear-dendritic laccase complexes. Biomacromolecules 2014, 15, 4082-4095. [CrossRef] [PubMed]

17. Scheibel, D.M.; Gitsov, I. Unprecedented enzymatic synthesis of perfectly structured alternating copolymers via "green" reaction cocatalyzed by laccase and lipase compartmentalized within supramolecular complexes. Biomacromolecules 2019, 20, 927-936. [CrossRef]

18. Gitsov, I.; Simonyan, A. “Green” synthesis of bisphenol polymers and copolymers, mediated by supramolecular complexes of laccase and linear-dendritic block copolymers. In Green Polymer Chemistry: Biocatalysis and Materials II; Cheng, H.N., Gross, R.A., Eds.; American Chemical Society: Washington, DC, USA, 2013; Volume 1144, pp. 121-139.

19. Bilal, M.; Rasheed, T.; Nabeel, F.; Iqbal, H.M.N.; Zhao, Y. Hazardous contaminants in the environment and their laccase-assisted degradation-A review. J. Environ. Manag. 2019, 234, 253-264. [CrossRef]

20. Claus, H.; Faber, G.; König, H. Redox-mediated decolorization of synthetic dyes by fungal laccases. Appl. Microbiol. Biotechnol. 2002, 59, 672-678. [CrossRef]

21. Maloney, J.; Dong, C.; Campbell, A.S.; Dinu, C.Z. Emerging enzyme-based technologies for wastewater treatment. In Green Polymer Chemistry: Biobased Materials and Biocatalysis; American Chemical Society: Washington, DC, USA, 2015; Volume 1192, pp. 73-75.

22. Cermola, F.; Dellagreca, M.; Iesce, M.R.; Montella, S.; Pollio, A.; Temussi, F. A mild photochemical approach to the degradation of phenols from olive oil mill wastewater. Chemosphere 2004, 55, 1035-1041. [CrossRef] [PubMed]

23. Schweigert, N.; Zehnder, A.J.B.; Eggen, R.I.L. Chemical properties of catechols and their molecular modes of toxic action in cells, from microorganisms to mammals. Environ. Microbiol. 2001, 3, 81-91. [CrossRef]

24. Wang, Q.; Cui, J.; Li, G.; Zhang, J.; Li, D.; Huang, F.; Wei, Q. Laccase immobilized on a PAN/adsorbents composite nanofibrous membrane for catechol treatment by a biocatalysis/adsorption process. Molecules 2014, 19, 3376-3388. [CrossRef]

25. Su, J.; Noro, J.; Fu, J.; Wang, Q.; Silva, C.; Cavaco-Paulo, A. Enzymatic polymerization of catechol under high-pressure homogenization for the green coloration of textile. J. Clean. Prod. 2008, 202, 792-798. [CrossRef]

26. Su, J.; Noro, J.; Fu, J.; Wang, Q.; Silva, C.; Cavaco-Paulo, A. Exploring PEGylated and immobilized laccases for catechol polymerization. AMB Expr. 2018, 8, 134. [CrossRef]

27. Aktas, N.; Sahiner, N.; Kantoglu, Ö.; Salih, B.; Tanyolac, A. Biosynthesis and characterization of laccase catalyzed poly(catechol). J. Polym. Environ. 2003, 11, 123-128. [CrossRef] 
28. Aktas, N.; Tanyolac, A. Reaction conditions for laccase catalyzed polymerization of catechol. Biores. Technol. 2003, 87, 209-214. [CrossRef]

29. Marczewska, B.; Przegalinski, M. Poly(catechol) electroactive film and its electrochemical properties. Synth. Met. 2013, 182, 33-39. [CrossRef]

30. Gavrilas, S.; Dumitriu, F.; Stanescu, M.D. Commercial laccase oxidation of laccase compounds. U.P.B. Sci. Bull. Ser. B Chem Mater. Sci. 2012, 74, 3-10.

31. Stanescu, M.D.; Gavrilas, S.; Ludwig, R.; Haltrich, D.; Lozinsky, V.I. Preparation of immobilized Trametes pubescens laccase on a cryogel-type polymeric carrier and application of the biocatalyst to apple juice phenolic compounds oxidation. Eur. Food Res. Technol. 2012, 234, 655-662. [CrossRef]

32. Piacquadio, P.; De Stefano, G.; Sammartino, M.; Sciancalepore, V. Phenols removal from apple juice by laccase immobilized on $\mathrm{Cu}^{2+}$-chelate regenerable carrier. Biotechnol. Tech. 1997, 11, 515-517. [CrossRef]

33. Hadzhiyska, H.; Calafell, M.; Gibert, J.M.; Daga, J.M.; Tzanov, T. Laccase-assisted dyeing of cotton. Biotechnol. Let. 2006, 28, 755-759. [CrossRef]

34. Kim, S.; Silva, C.; Evtuguin, D.V.; Gamelas, J.A.F.; Cavaco-Paulo, A. Polyoxometalate/laccase-mediated oxidative polymerization of catechol for textile dyeing. Appl. Microbiol. Biotechnol. 2011, 89, 981-987. [CrossRef] [PubMed]

35. Shin, H.; Guebitz, G.; Cavaco-Paulo, A. In situ enzymatically prepared polymers for wool coloration. Macromol. Mater. Eng. 2001, 286, 691-694. [CrossRef]

36. Fatarella, E.; Spinelli, D.; Ruzzante, M.; Pogni, R. Nylon 6 film and nanofiber carriers: Preparation and laccase immobilization performance. J. Mol. Catal. B Enzym. 2014, 102, 41-47. [CrossRef]

37. Jasni, M.J.F.; Sathishkumar, P.; Sornambikai, S.; Yusoff, A.R.M.; Ameen, F.; Buang, N.A.; Kadir, M.R.A.; Yusop, Z. Fabrication, characterization and application of laccase-nylon $6,6 / \mathrm{Fe}^{3+}$ composite nanofibrous membrane for 3,30-dimethoxybenzidine detoxification. Bioprocess Biosyst. Eng. 2017, 40, 191-200. [CrossRef] [PubMed]

38. Silva, C.; Silva, C.J.; Zille, A.; Guebitz, G.M.; Cavaco-Paulo, A. Laccase immobilization on enzymatically functionalized polyamide 6,6 fibers. Enzym. Microb. Technol. 2007, 41, 867-875. [CrossRef]

39. Dencheva, N.; Denchev, Z.; Lanceros-Méndez, S.; Ezquerra, T.A. One-step in-situ synthesis of polyamide microcapsules with inorganic payload and their transformation into responsive thermoplastic composite materials. Macromol. Mater. Eng. 2016, 301, 119-124. [CrossRef]

40. Cano-Raya, C.C.; Dencheva, N.V.; Braz, J.F.; Malfois, M.; Denchev, Z. Optical biosensor for catechol determination based on laccase-immobilized anionic polyamide 6 microparticles. J. Appl. Polym. Sci. 2020, 137, 49131. [CrossRef]

41. Dencheva, N.; Braz, J.; Nunes, T.G.; Oliveira, F.D.; Denchev, Z. One-pot low temperature synthesis and characterization of hybrid poly(2-pyrrolidone) microparticles suitable for protein immobilization. Polymer 2018, 145, 402-4015. [CrossRef]

42. Dencheva, N.V.; Oliveira, F.D.; Braz, J.F.; Denchev, Z. Bovine serum albumin-imprinted magnetic poly(2-pyrrolidone) microparticles for protein recognition. Eur. Polym. J. 2020, 122, 109375. [CrossRef]

43. Dencheva, N.; Braz, J.; Scheibel, D.; Malfois, M.; Denchev, Z.; Gitsov, I. Polymer-assisted biocatalysis: Polyamide 4 microparticles as promising carriers of enzymatic function. Catalysts 2020, 10, 767. [CrossRef]

44. Oliveira, F.M.; Dencheva, N.V.; Lanceros-Méndez, S.; Nunes, T.G.; Denchev, Z. Binary Polyamide Hybrid Composites Containing Carbon Allotropes and Metal Particles with Radiofrequency Shielding Effect. Polym. Compos. 2019, 40, E1338-E1352. [CrossRef]

45. Liers, C.; Ullrich, R.; Pecyna, M.; Schlosser, D.; Hofrichter, M. Production, purification and partial enzymatic and molecular characterization of a laccase from the wood-rotting ascomycete Xylaria polymorpha. Enzym. Microb. Technol. 2007, 41, 785-793. [CrossRef]

46. Atalla, M.; Zeinab, H.; Eman, R.; Amani, A.; Abeer, A. Characterization and kinetic properties of the purified Trematosphaeria mangrovei laccase enzyme. Saudi J. Bioll. Sci. 2013, 20, 373-381. [CrossRef] [PubMed]

47. Costa, J.; Lima, M.J.; Sampaio, M.J.; Neves, M.C.; Faria, J.L.; Morales-Torres, S.; Tavares, A.P.M.; Silva, C.G. Enhanced biocatalytic sustainability of laccase by immobilization on functionalized carbon nanotubes/polysulfone membranes. Chem. Eng. J. 2019, 355, 974-985. [CrossRef]

48. Qiu, H.; Xu, C.; Huang, X.; Ding, Y.; Qu, Y.; Gao, P. Immobilization of laccase on nanoporous gold: Comparative studies on the immobilization strategies and the particle size effects. J. Phys. Chem. C 2009, 113, 2521-2525. [CrossRef]

49. Piontek, K.; Antorini, M.; Choinowski, T. Crystal structure of a laccase from Trametes versicolor at $1.90 \AA$ A resolution containing a full complement of coppers. J. Biol. Chem. 2002, 277, 37663-37669. [CrossRef] [PubMed]

50. Dencheva, N.; Nunes, T.; Oliveira, M.J.; Denchev, Z. Microfibrillar composites based on polyamide/polyethylene blends. 1. Structure investigations in oriented and isotropic PA6. Polymer 2005, 46, 887-901. [CrossRef]

51. Fornes, T.D.; Paul, D.R. Crystallization behavior of Nylon nanocomposites. Polymer 2003, 44, 3945-3961. [CrossRef]

52. Bartczak, Z.; Galeski, A.; Argon, A.S.; Cohen, R.E. On the plastic deformation of the amorphous component in semicrystalline polymers. Polymer 1996, 37, 2113-2123. [CrossRef]

53. Alexander, L.E. X-ray Diffraction Methods in Polymer Science; Wiley-Interscience: New York, NY, USA, 1969.

54. Bolivar, J.M.; Consolati, T.; Mayr, T.; Nidetzky, B. Shine a light on immobilized enzymes: Real-time sensing in solid supported biocatalysts. Trends Biotechnol. 2013, 31, 194-203. [CrossRef] [PubMed]

55. Arantes, V.; Milagres, A.M.F. The synergistic action of ligninolytic enzymes (MnP and Laccase) and Fe ${ }^{3+}$-reducing activity from white-rot fungi for degradation of Azure B. Enzym. Microb. Technol. 2007, 42, 17-22. [CrossRef] 
56. Wang, Q.; Peng, L.; Li, G.; Zhang, P.; Li, D.; Huang, F.; Wei, Q. Activity of laccase immobilized on TiO 2 -Montmorillonite complexes. Int. J. Mol. Sci. 2013, 14, 12520-12532. [CrossRef]

57. Johannes, C.; Majcherczyk, A. Natural mediators in the oxidation of polycyclic aromatic hydrocarbons by laccase mediator systems. Appl. Environ. Microbiol. 2000, 66, 524-528. [CrossRef] [PubMed]

58. Sun, X.; Bai, R.; Zhang, Y.; Wang, Q.; Fang, X.; Yuan, J.; Li, C.; Wang, P. Laccase-catalyzed oxidative polymerization of phenolic compounds. Appl. Biochem. Biotechnol. 2013, 171, 1673-1680. [CrossRef]

59. Ito, S.; Sugumaran, M.; Kazumasa, W. Chemical reactivities of ortho-quinones produced in living organisms: Fate of quinonoid products formed by tyrosinase and phenoloxidase action on phenols and catechols. Int. J. Mol. Sci. 2020, 21, 6080. [CrossRef]

60. Singleton, V.L.; Orthofer, R.; Lamuela-Raventós, R.M. Analysis of total phenols and other oxidation substrates and antioxidants by means of folin-ciocalteu reagent. Meth. Enzymol. 1999, 299, 152-178.

61. Su, J.; Castro, T.G.; Noro, J.; Fu, J.; Wang, Q.; Silva, C.; Cavaco-Paulo, A. The effect of high-energy environments on the structure of laccase polymerized poly(catechol). Ultrason. Sonochem. 2018, 48, 275-280. [CrossRef]

62. Song, J.E.; Su, J.; Noro, J.; Cavaco-Paulo, A.; Silva, C.; Kim, H.R. Bio-coloration of bacterial cellulose assisted by immobilized laccase. AMB Expr. 2018, 8, 19-30. [CrossRef]

63. González, J.B.; González, N.; Colldelram, C.; Ribó, L.; Fontserè, A.; Manas, G.J.; Villanueva, J.; Llonch, M.; Peña, G.; Gevorgyan, A.; et al. NCD-SWEET beamline upgrade. In Proceedings of the 10th Mechanical Engineering Design of Synchrotron Radiation Equipment and Instrumentation Conference, Paris, France, 25-29 June 2018; pp. 374-376.

64. Ashiotis, G.; Deschildre, A.; Nawaz, Z.; Wright, J.P.; Karkoulis, D.; Picca, F.E.; Kieffer, J. The fast azimuthal integration Python library: pyFAI. J. Appl. Crystallogr. 2015, 48, 510-519. [CrossRef] [PubMed]

65. Agbor, G.A.; Vinson, J.A.; Donnelly, P.A. Folin-Ciocalteau reagent for polyphenolic assay. Int. J. Food Sci. Nutr. Diet. 2014, 3, 147-156. [CrossRef] 